\title{
El Interior frente a Buenos Aires: flujos comerciales e integración económica, 1831-1850*
}

\author{
Miguel A. Rosal \\ CONICET-INSTTIUTO DE HISTORIA \\ ARgentiNA Y AMERICANA "DOCTOR EMILIO RAVIgNANI"
}

Para esclarecer si fue inevitable la articulación del espacio rioplatense con el Atlántico -lo que inclinó la balanza a favor de Buenos Aires-, en este ensayo se analizan las conexiones comerciales que se forjaron con el reacomodamiento del sistema económico poscolonial en las provincias que constituirian la Argentina.

INTRODUCCIÓN

L as guerras de Independencia que siguieron al estallido revolucionario de 1810 trastocaron de tal modo los circuitos mercantiles coloniales que, cuando finalizaron, se había quebrado el principal eje (Potosí-Buenos Aires) sobre el cual giraban las

*Agradezco los comentarios que, sobre resultados parciales de esta investigación, me hicicron José Carlos Chiaramonte, Juan Carlos Garavaglia, Silvia Palomeque, Silvia Romano y Roberto Schmit, así como los de José Carlos Chiaramonte y Ruggicro Romano, sobre la versión fìnal. economías regionales rioplatenses. Así, mientras una parte del espacio iba entretejiendo un firme vínculo con los mercados de ultramar, simultáneamente se desarticulaba el que se había estructurado a lo largo de tres siglos en torno a la riqueza minera altoperuana. Este proceso, dados los recursos naturales y ubicación geográfica de las diversas regiones, si bien benefició a la zona bonaerense-litoraleña, produjo considerables perjuicios económicos en el interior del espacio en cuestión. Con la emancipación y la vinculación plena con Europa, se produjo una competencia desfavorable 
para las artesanías, dados el bajo precio y la mejor calidad de los productos industrializados, a la vez que desapareció o, al menos, se redujo drásticamente su comercio con extensas zonas del viejo orden colonial. De todos modos, la competencia ultramarina no parece haber castigado de la misma manera a dichas artesanias; algunas fueron sofocadas, como el textil de algodón catamarqueño; otras, contenidas en su expansión hasta hacerlas retroceder y reducirlas a mínimas expresiones, como sucedió con la vitivinicultura cuyana (aunque en este caso coadyuvó la guerra civil) y, en el mejor de los casos, otras fueron golpeadas duramente, aunque con larga supervivencia, como la artesanía textil de lana de Córdoba y Santiago del Estero. En síntesis, "la ruina de las artesanías, supuesta consecuencia necesaria de la liberalización comercial, no parece haber sido[...] ni tan rápida, ni tan completa como se supone a veces". ${ }^{1}$ Más adelante volveremos sobre el tema de los caldos y tejidos "de la tierra".

De cualquier modo, para las provincias interiores se tornaba imperativo adoptar medidas proteccionistas que de haberse establecido hubieran implicado el riesgo de una merma de volumen del comercio exterior y un aumento del precio de los artículos de consumo, consecuencias indeseadas por Buenos Aires, largamente beneficiada con el proceso abierto en 1810 y a la que poco importaba la situación del Interior. En efecto, el puerto, indi156.

1 Halperin Donghi, Revolucion, 1980, p. ferente a la adversidad que atravesaban las provincias, disfrutaba de un periodo de expansión económica basada en la ganadería, cuyos productos eran altamente apreciados como materia prima por la industrialización europea. Mantenía, además, el control sobre los derechos aduaneros $\mathrm{y}$, al prohibir la libre navegación de los ríos interiores, se reservaba los servicios de intermediación, a lo que se agregaba la disposición de una política arancelaria sui géneris -en tanto surgida de la administración rosista, supuestamente federal-, al menos desde el punto de vista de los provincianos. En realidad, "en el Buenos Aires de Rosas existían pocas libertades, pero el libre comercio era una de ellas". ${ }^{2}$

El Litoral, semejante a la región bonaerense en recursos y posibilidades económicas, se adaptó mucho mejor a las nuevas reglas de juego. Sin embargo, el concepto de "libertad de comercio" que tenían las provincias litoraleñas era bastante más amplio que el que manejaban los porteños. El de aquéllas incluía la libertad de navegación de los ríos, que les hubiera permitido obviar los servicios del puerto de Buenos Aires y, sobre todo, los de intermediación. De alli que "para el interior la revolución de 1810 fue demasiado lejos; para el litoral no fue bastante lejos". 3

En cualquier caso, no obstante los distintos enfoques sobre el desarrollo

\footnotetext{
2 Lynch, "Repúblicas", 1991, p. 272.

3 Burgin, Aspectos, 1987, p. 167. Recordemos de todos modos que, aun para una provincia litoraleña como Corrientes, la cuestión arancelatia era primordial.
} 
económico más conveniente, las provincias coincidian en que la recaudación aduanera debería ser administrada por un poder central y no por una sola provincia, y que para ello se necesitaba una organización nacional y una constitución que la rigiera, para así cercenar los privilegios porteños y atender a los intereses de todos los estados provinciales. Estas divergencias tuvieron su trágica culminación en las luchas civiles, y en tanto las provincias no contaran con la fuerza necesaria para doblar el brazo bonaerense deberían resignarse comprometiendo su participación en diversos espacios mercantiles, ya que después de todo era una cuestión de supervivencia económica. ${ }^{4}$

Es así como, ya fuera en función de su producción, de la distancia, o de ambas cosas a la vez, se fueron inclinando hacia los distintos mercados surgidos del reacomodamiento del sistema económico poscolonial. En tanto el Litoral no dudó de que saldría beneficiado al articularse con el Atlántico, ${ }^{5}$ las provincias norteñas de lo que más tarde sería la Argentina, por su parte, conformaron la periferia de un nuevo espacio mercantil, cuyo núcleo se asentaba en el antiguo Alto Perú (aun con ocasionales envíos, ya fueran directos a Buenos Aires o se dirigieran a Córdoba, la cual los reexportaba hacia el puerto), mientras que las cuyanas, no obstante sus conexio-

Langer y Conti, Circuitos, 1991, p. 93.

5 Incluso las provincias litoraleñas, en especial Corrientes, buscaban la apertura hacia mercados externos, por ejemplo, el nuevo estado oriental. nes con dicho mercado, parecían más predispuestas a recostarse sobre el Pacífico.

Así presentado el problema -y más allá de algunas concesiones casi arrancadas a Buenos Aires, como en el caso de la Ley de Aduanas de 1835- ifue inevitable que la balanza se inclinara hacia el puerto? Si bien no existen cifras concretas respecto a los flujos mercantiles hacia las salidas alternativas hacia el mercado porteño, la articulación plena del espacio rioplantense con el Atlántico parecía ser sólo cuestión de tiempo; sin embargo, el peligro de desintegración económica del mismo estaba siempre latente. En todo caso, el análisis de las conexiones comerciales con Buenos Aires puede aportar una mejor comprensión de los cambios operados a partir de 1810.

En ese sentido, el presente trabajo estudiará el comportamiento y naturaleza del flujo comercial desde el Interior hacia el puerto de Buenos Aires y la participación que correspondió a cada región en la constitución total del mismo; en un periodo por demás azaroso enmarcado por las luchas entre unitarios y federales, en el plano interno, y por los bloqueos francés y anglofrancés - amén de los conflictos con el Uruguay y la Confederación Peruano-Boliviana, entre otros-, en el externo. El objetivo será ilustrar las conexiones comerciales existentes entre las distintas provincias de la confederación y su capital durante la extensa etapa rosista; ello permitirá entrever la relación casi exclusiva en algunos casos, más débil en otros, que fueron entretejiendo las diversas re- 
giones-provincias con Buenos Aires en esa lenta incorporación de mercados regionales que subyace en toda formación de un mercado nacional.

Antecedentes significativos sobre este tipo de estudio se pueden hallar en la obra de Miron Burgin ${ }^{6}$ y en la de Carlos Sempat Assadourian, que analiza el flujo exportador cordobés durante las primeras seis décadas del siglo pasado. ${ }^{7}$ Otros valiosos aportes son los recientes estudios de José Carlos Chiaramonte $^{8}$ y Roberto Schmit ${ }^{9}$ sobre Corrientes, además de aquellos referidos a un periodo anterior al que abarca nuestro trabajo. ${ }^{10}$

De todos modos, observamos que no ha sido mucho lo que se ha trabajado sobre flujos comerciales en gran escala ${ }^{11}$ y prácticamente nada si nos referimos a flujos mercantiles totales en función del monto comerciado y de la totalidad del espacio económico rioplantense, al menos para el periodo elegido. ${ }^{12}$ Es por ello que al encarecer el estudio de la dirección de

6 Burgin, Aspectos, 1987,

${ }^{7}$ Assadourian, "Sector", 1983, pp. 307, 367.

${ }^{8}$ Chiaramonte, Mercaderes, 1991.

9 Schmit, "Mercados", 1991, pp. 31-61.

10 Entre otros, podemos citar los de Wentzel, "Comercio", 1989, pp. 161-210, Amaral, "Comercio", 1990, pp. 167, y Palomeque, 1990, "Circulación", pp. 131-210.

11 Una aproximación al tema se puede hallar en los trabajos de Mallo, "Comercio", 1973, pp. 263-266, Blasi, "Relaciones", 1973, pp. 277285, y Cano et al., "Comercio", 1973, 287-304. Los mismos están basados en el análisis de $\mathbf{L a}$ Gaceta Mercantll, que si bien no puede ser despreciada como fuente para el tratamiento del tema en cuesitón, en comparación con las que revisamos parece mucho menos rica.

$12 \mathrm{El}$ presente trabajo trata de integrar los frutos de una extensa investigación: "Río de la dichos flujos hacia el principal puerto exportador del espacio en cuestión, nuestro trabajo puede llegar a aportar -creemos-algunas cifras e ideas que ayuden al esclarecimiento del tema.

\section{LAS FUENTES}

La división temporal propuesta (1831$1835,1836-1838$ y $1839-1850)$ para la realización de este estudio obedece a la imposibilidad de utilizar una misma fuente principal para todo el periodo.

Entre 1831 y agosto de 1835 hemos recogido los datos brindados por los libros de Contribución Directa -conservados en el Archivo General de la Nación- constituidos por los manifiestos que presentaban los consignatarios de Buenos Aires en la aduana porteña para retirar las mercancías, $y$ en donde se asienta el valor de la "contribución directa", impuesto que alcanzaba $4 \%$ (cuatro por mil) del total de los precios de aforo de los productos, aparentemente bien ordenados y completos (sólo faltan los correspondientes al primer bimestre de 1833). ${ }^{13}$

Los datos que más nos interesaba extraer eran: origen de la carga, monto comerciado de cada nota o mani-

Plata", Boletin del IHAA "Dr. Emilio Ravignani", 1992, pp. 49-75; "Río de la Plata", Revista de Historia de America, 1992; "Río de la Plata", 1993, mimeografiado.

13 En realidad, el año 1831 comienza con el manifiesto 820 y al final de ese año está, obviamente fuera de lugar, el número 815 con fecha 30-12-1830, lo que invita a pensac que los numerados entre el 1 y el 819 corresponden, muy probablemente, a los años 1829 y 1830 , pero hasta el momento no han sido hallados. 
fiesto, cantidad de cueros, tejidos, caldos, lana, tasajo, etc., $y$, de ser posible, el precio por unidad de los mismos. Cada manifiesto en cuestión fue considerado como una operación, y bajo esta denominación, consignado en nuestro trabajo. También se pueden encontrar, entre dichas notas, algunas pocas guías de origen, es decir, guias de comercio extendidas en el lugar de donde partió el cargamento.

Por decreto del 15 de septiembre de 1835 se declaran libres de impuesto de Contribución Directa los frutos y efectos "de la República", introducidos a Buenos Aires por agua o tierra (con excepción de la yerba mate y el tabaco), por lo que para completar dicho año nos servimos de cuatro legajos de comprobantes de cargo de la cuenta de la Receptoría General. ${ }^{14}$

Para el estudio del lapso $1836-38$ recurrimos al Registro Oficial de la Provincia de Buenos Aires, que aporta datos que van desde el segundo se-

${ }^{14}$ Los mismos documentan la llegada a Buenos Aires de considerables cargamentos de tabaco y yerba -cosa que no habíamos observado hasta ese momento-desde las subregiones que hemos denominado "Uruguay", "Entre Rios" y "Corrientes", por lo cual el monto comerciado total de las mismas tuvo cierto incremento respecto de las demás, sobre las cuales no hemos obtenido noticia alguna. Como contrapartida, hemos hallado unos pocos casos en que, en virtud del decreto antedicho, se deja de lado el cobro de impuestos (y la valuación) de cueros y suelas. Cabe agregar que los lugares de origen de la yerba y el tabaco eran Corrientes, Misiones y Paraguay; los productos de este último se canalizaban a través de los puertos orientales sobre el Uruguay, en especial, Salto. En cuanto a los legajos de comprobantes, existen doce (uno para cada mes) correspondientes a 1836, pero brindan muy pocos datos significativos. mestre de 1835 al primero de 1840 , si bien los del primero de los citados y los del primer semestre de 1836 no pudieron utilizarse ya que no están desagregados. En definitiva, obtuvimos cifras globales (y no regionales, como era nuestro deseo) sobre la segunda mitad de 1836 y los años 1837 y 1838. En algún sentido, este lapso es el más oscuro de nuestra investigación, lo que es de lamentar en grado sumo pues no podemos apreciar con exactitud la reacción de las provincias ante la Ley de Aduanas de 1835.

Por ley del 12 de abril de 1839 . llamada de Contribución Directa, comienza a cobrarse nuevamente el impuesto por lo que a partir de mayo se pueden obtener los datos, ahora sí ininterrumpidamente, hasta 1850 , a través de varios legajos -también del Archivo General de la Nación- de la Receptoría General, Cargo y Data, sección Contribución Directa, constituidos por manifiestos similares a los de los "libros" de principios de la década, aunque más completos, en tanto consignan "precios" de aforo de los efectos y frutos en la mayoría de los mismos.

Por último, debemos decir que las fuentes en cuestión están citadas al pie de los cuadros de "flujos" (cuadros 1,5 y 9) y que en ellas se basan los distintos cuadros y gráficas de cada lapso en que fue dividido el trabajo.

Creemos que es interesante transcribir el concepto que Assadourian ha aportado sobre la utilización de este tipo de fuentes:

El uso de estos "precios" fiscales puede ser algo más que una tosca aproxima- 


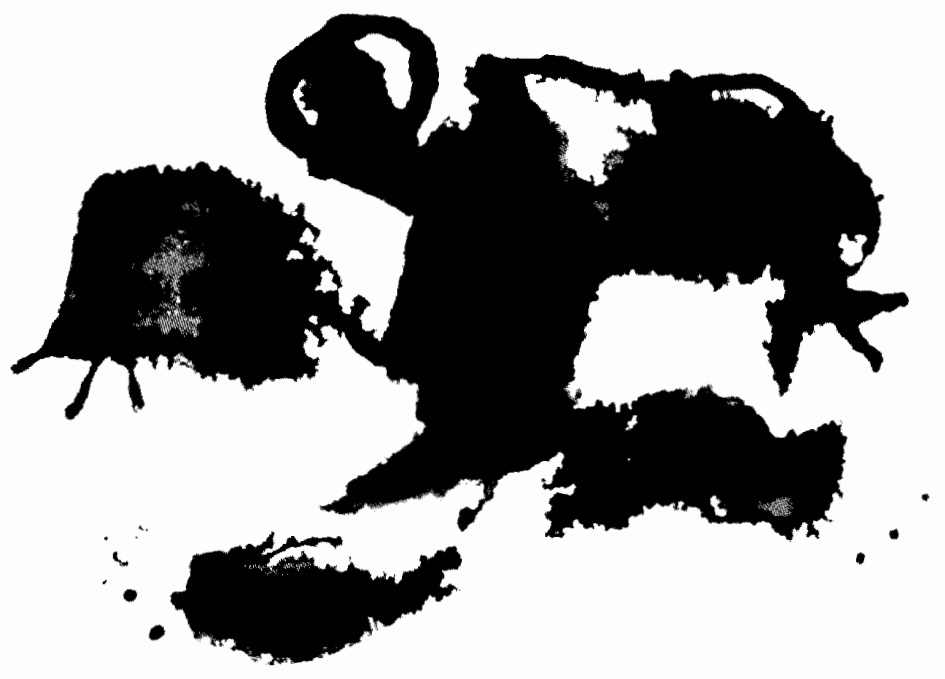

ción a la realidad, hasta creemos que para ciertos periodos reflejan con bastante fidelidad las variaciones significativas e incluso los accidentes circunstanciales de los precios del mercado al por menor.

De todos modos, al realizar estudios de esta naturaleza no debemos hacernos demasiadas ilusiones sobre una reconstrucción cuantitativa "total". En ese sentido, los problemas con que se encontró el citado autor en su trabajo sobre Córdoba son bastante ilustrativos: en primer lugar, el contrabando, pues "aun poseyendo los datos completos sobre el flujo mercantil legal lo que alcanzamos es una buena aproximación y nunca la precisión ab- soluta respecto a la totalidad de la circulación mercantil (la legal más la ilegal)"; en segundo lugar, la "imperfección de las fuentes". 15

\section{REGIONES Y SUBREGIONES}

Para facilitar el análisis del comportamiento y naturaleza del flujo comercial que desde el Interior se dirigía al principal puerto exportador del país hemos dividido el espacio en tres grandes bloques o regiones, los cuales a su vez fueron fraccionados en subre. giones que, salvo casos muy puntuay 314 .

15 Assadourian, "Sector", 1983, pp. 308-309 
les, coinciden geográficamente con los distintos territorios provinciales de la confederación rosista. Esto, por su parte, coadyuvará a comprender el trasfondo político -léase, incesantes reclamos regionales en torno a las cuestiones fundamentales de la nacionalización de la aduana, libre navegación de los ríos y, en fin, organización constitucional, a los cuales Buenos Aires no tendrá más remedio que prestarles atención, ya fuese para hacer concesiones parciales $\mathrm{o}$, en casos extremos, para acallarlos por medio de las armas- de un aspecto meramente económico, como pueden ser las relaciones comerciales.

\section{Litoral}

Esta región, que por su dinamismo económico es sin duda la más importante de las tres aquí consideradas, está dividida en tres subregiones/provincias (Santa Fe, Corrientes y Entre Ríos) y tres subregiones determinadas en función de los datos hallados (una pequeña fracción de la campaña bonaerense del norte, próxima a la costa del Paraná; la franja litoraleña recostada sobre el río Uruguay, en el territorio de la antigua Banda Oriental y la zona sureña del Paraguay, subregión sobre la cual de todos modos no poseemos demasiados datos, y todos los hallados corresponden a la década de 1840 , cuando dicho país comienza a salir de su aislacionismo, luego del fallecimiento de Gaspar Rodriguez de Francia).

Buenos Aires: llamada así por formar parte - pequeña, en realidad-de la campaña norte ${ }^{16}$ de la provincia de Buenos Aires, cercana a la zona costera del río Paraná, cuyos puertos (en especial, San Nicolás, pero también Baradero, San Pedro y Zárate) se destacan en la conexión comercial con la capital; además, cumplirán el papel de puntos de enlace entre la producción del interior y la capital, por medio de la correspondencia establecida entre el transporte terrestre -especialmente el dispuesto a través de arrias-y el fluvial.

Santa Fe: tanto la capital provincial como el puerto de Rosario son centros excluyentes de la producción y comercialización santafesina, ${ }^{17}$ a lo que deben agregar su papel reexportador correspondiente a las mercancías que provienen de la región Central y desde Cuyo, como también a la producción maderera litoraleña.

Corrientes: los puertos correntinos sobre el Paraná (Esquina, Goya, Bella Vista y, en especial, el capitalino) son los que concentran la actividad exportadora de la provincia. No hemos recogido información similar referente a la orilla opuesta, es decir la recostada sobre el río Uruguay. Sospechamos que al menos parte de la producción misionera se canalizaba a través de comerciantes correntinos; sin embar-

16 En las fuentes consultadas, en especial entre 1831 y 18,35 , aparecen unos pocos envíos desde la campaña sur de la provincia de Buenos Aires ("el Tullú", Bahía Blanca, Patagones); los mismos consisten en cueros, sal y cereales, principalmente.

17 Existen unos pocos datos referentes a otras localidades, como por ejemplo, San Lorenzo. 
go, esa situación no aparece claramente especificada en las fuentes. Corrientes fue quizá la que más impugnó la política económica determinada desde Buenos Aires, que la llevó a sangrientos enfrentamientos con la misma, los cuales sin duda repercutieron negativamente sobre su economía, al punto de que su conexión comercial con el puerto fue en ocasiones bastante débil y por momentos inexistente

Entre Ríos: esta subregión se puede dividir en dos zonas, similares en cuanto a la producción, aunque las diferencias se irán marcando en lo que se refiere a la dinámica económica, a lo largo del periodo en estudio. La primera de ellas, una franja costera sobre el Paraná, identificada con dicho nombre, tiene a la Bajada como el principal puerto exportador. La segunda es la "costa occidental del río Uruguay", con varios puertos (Mandisoví-Concordia, Arroyo de la ChinaConcepción del Uruguay, Gualeguaychú) que se destacan en la conexión comercial con la capital rosista. Tal como sucedia con Corrientes, es posible que esta zona canalizara parte de la producción misionera (e incluso correntina) llegada desde río arriba, pero una vez más las fuentes no son, salvo contadas excepciones, lo suficientemente precisas al respecto. ${ }^{18}$ Lo que sí podemos adelantar es que tuvo a partir de la década de 1840 un crecimiento económico tal, que la lle-

18 Refìriéndose a Corrientes, Chiaramonte expresa que "la falta de control político de la provincia sobre su despoblada franja oriental" hacía que el comercio por el río Uruguay esca- vó a ubicarse como una de las más importantes de todo el espacio estudiado. Por medio de esta división zonal podrán compararse los flujos que bajaban, no ya a través de los dos grandes ríos sino, más aún, los provenientes de cada una de las orillas de los mismos. Juntas, es decir "Paraná" y "costa occidental del río Uruguay", conforman la subregión más significativa de todas las analizadas en el presente trabajo.

Uruguay: tal como hemos anticipado, se trata de la franja costera sobre el río del mismo nombre, esta vez en territorio perteneciente a la antigua Banda Oriental, con varios puertos que participaban en el tráfico comercial, por ejemplo: Salto, Paysandú, Mercedes, Colonia, etc. Políticamente, dicho territorio ya formaba parte de la República Oriental del Uruguay; sin embargo, los lazos económicos con la antigua capital virreinal eran considerablemente estrechos, al punto de convertir a esta subregión en la segunda en importancia en cuanto al volumen comerciado. De allí su inclusión en este estudio.

Paraguay: si bien la información no es demasiado abundante, hemos recogido datos sobre algunos envios, principalmente desde la zona sureña paraguaya (aunque también registramos unas pocas remesas desde la capital, Asunción), de un limitado número de cueros vacunos y suelas, a partir del tercer lapso en que fue dividido este trabajo.

para a cualquier propósito de regulación; sólo a partir de 1830 se efectuarían los primeros intentos de revertir la situación. Véase Chiaramonte, Mercaderes, 1991, p. 70. 


\section{Central}

Esta región aparece mucho más comprensible en su división geográfica en subregiones, pues las mismas están conformadas por las distintas provincias: Córdoba, Santiago del Estero, Tucumán, Salta, Jujuy, Catamarca y La Rioja. Aun antes de finalizar las guerras de la Independencia, comenzaron a recomponerse los circuitos mercantiles norteños configurándose así un nuevo espacio económico andino, heredero raquítico del potosino colonial, y al cual se integraron varias de las mencionadas subregiones como una periferia sureña del mismo. Existieron, para ello, varias razones: en especial, la escasa posibilidad que tenían los productos del interior de competir en el mercado porteño con los artículos importados de ultramar, generalmente más baratos y de mejor calidad. Pero también incidía la falta de moneda metálica, la cual podía ser provista sólo por la región altoperuana, pronto convertida en la República de Bolivia. ${ }^{19}$ En todo caso, como señalan Langer y Conti, no quedaban demasiadas alternativas. ${ }^{20} \mathrm{De}$ cualquier manera,

19 "La plata boliviana, que circuló como moneda y como mercancía, constituye un elemento esencial para entender la preservación de este espacio económico durante el siglo xix." La misma "circuló por un amplio espacio mercantil que [...] abarcó el sur del Perú, toda Bolivia y el norte de la Argentina". Véase Langer y Conti, "Circuitos", 1991, p. 96.

20 "Al estructurarse el nuevo espacio mercantil andino, la oligarquía terrateniente-comercial del noroeste -especialmente Jujuy y Saltavio allí la única posibilidad de superviviencia que la coyuntura le ofrecía", ibid., p. 94. no debe exagerarse la importancia de la fuerza y el tamaño de este mercado interno [pues] [...] tenía serias debilidades que provocaron su rápida desaparición en la segunda mitad del siglo XIX. ${ }^{21}$

De todos modos, hasta la década de 1860, Salta tenía un comercio de exportación más importante con Bolivia y Perú que con las provincias argentinas. ${ }^{22}$ Catamarca, La Rioja y, especialmente, Tucumán comprometían su participación en diversos espacios mercantiles: obviamente, el Alto y el Bajo Perú (Bolivia y Perú, respectivamente), pero también Cuyo (y su enlace con el Pacífico), aunque sin olvidar los débiles lazos que las unian al puerto. En realidad, sólo Córdoba era la que había ingresado, a partir de 1830-1835, en una "etapa de articulación absoluta con el Atlántico"; ${ }^{23}$ el panorama del resto de la región indicaba que era inestable aquella aparentemente lograda integración económica de $1835,{ }^{24}$ que sólo se cimentará con la llegada del ferrocarril a las zonas más alejadas de lo que será la nación argentina.

\section{Cuyo}

Está integrada por tres subregiones/provincias (Mendoza, San Juan y San Luis), lo que significa que hemos mantenido la división geográfica tradi-

\footnotetext{
21 Langer, "Espacios", 1987, pp. 144-145.

22 Ibid., p. 144.

23 Assadourian, "Sector", 1983, p. 366.

24 Halperin Donghi, Revolucion, 1972, p. 83.
} 
cional, pues en verdad la producción exportada a Buenos Aires de las dos primeras se diferencia considerablemente de aquella enviada por los puntanos, bastante similar a la de Córdoba aunque, claro está, muchísimo menos abundante que la de esta última. De cualquier modo, las tres parecerían tener problemas similares a los que soportaban sus hermanas de la región central en su vinculación económica con el puerto de Buenos Aires. Tanto unas como otras, sólo en la época de los bloqueos pudieron acercar sus productos -aunque en la medida de sus posibilidades, por cierto nada excepcionales - a la aduana porteña. En tiempos normales, el único desahogo económico ante la asfixiante situación cuyana era la vinculación con Chile. La misma fue de un nivel considerable, incluso en las épocas en que se establecieron prohibiciones, emanadas ya de Santiago, ya de Buenos Aires (aunque principalmente de esta última). No obstante, los contactos, ya fueran legales o no, aumentaban el peligro de la disgregación del espacio económico.

LAPSO 1831-1835

\section{Los flujos comerciales}

A través del cuadro 1 podemos observar la significativa participación que le cabe a Entre Ríos (24.20\%) en la composición total del flujo comercial hacia el puerto; a la vez notamos la importancia que en la misma tenían la franja costera sobre el Uruguay de la antigua Banda Oriental (15.55\%) y Corrientes (13.02\%).

Asimismo, nos llama la atención el registro de Santa Fe (7.70\%), que podría considerarse bajo si pensamos que a fines del periodo estudiado por Wentzel había cobrado un dinamismo similar al que tenía en los tiempos en que gozó de los privilegios del "puerto preciso", justamente por haberse convertido en el nexo entre la retraída Asunción y Buenos Aires. ${ }^{25}$ Más aún, si tenemos en cuenta que Santa Fe canalizaba una parte -si bien no demasiado importante- de la producción de las áreas central y cuyana.

La situación de la subregión Buenos Aires es, por su parte, muy particular; aunque su participación en el total del monto no es espectacular, ni mucho

Participación del "litoral de los ríos" en el total del monto comerciado, 1831-1835

Río Paraná

\begin{tabular}{|c|c|}
\hline $\begin{array}{c}\text { Costa occidental } \\
\text { (Bs.As.S.Fe) }\end{array}$ & $\begin{array}{l}\text { Costa oriental } \\
\text { (Ctes.-Paraná) }\end{array}$ \\
\hline $9.74-7.70 \%$ & $13.02-12.49 \%$ \\
\hline $17.44 \%$ & $25.51 \%$ \\
\hline
\end{tabular}

Río Uruguay

\begin{tabular}{|c|c|}
\hline $\begin{array}{l}\text { Costa occtdental } \\
\text { (Entre Ríos) }\end{array}$ & $\begin{array}{c}\text { Costa oriental } \\
\text { (Uruguay) }\end{array}$ \\
\hline $11.71 \%$ & $15.55 \%$ \\
\hline
\end{tabular}

${ }^{25}$ Wentzel, "Comercio", 1989, p. 180. 
Cuadro 1. Flujo comercial hacia Buenos Aires: total de valores comerciados, $1831-1835^{\mathrm{a}}$

\begin{tabular}{|c|c|c|c|c|}
\hline Regiones & Subregiones & Monto* & $\begin{array}{l}\text { Porcentaje } \\
\text { regional }\end{array}$ & $\begin{array}{c}\text { Porcentaje } \\
\text { total }\end{array}$ \\
\hline \multirow{6}{*}{ Lttoral } & Buenos Aires & 2956929 & 13.87 & 9.74 \\
\hline & Santa Fe & 2340446 & 10.99 & 7.70 \\
\hline & Corrientes & 3951.172 & 18.54 & 13.02 \\
\hline & Entre Ríos ${ }^{\mathbf{b}}$ & 7345264 & 34.46 & 24.20 \\
\hline & Uruguay & 4718952 & 22.14 & 15.55 \\
\hline & Total regional & 21312763 & 100.00 & 70.21 \\
\hline \multirow{8}{*}{ Central } & Córdoba & 5025310 & 67.56 & 16.56 \\
\hline & Santiago del Estero & 450050 & 6.05 & 1.48 \\
\hline & Tucumán & 1398895 & 18.81 & 4.61 \\
\hline & Salta & 430200 & 5.78 & 1.42 \\
\hline & Jujuy & 50200 & 0.67 & 0.17 \\
\hline & Catamarca & 59200 & 0.80 & 0.19 \\
\hline & La Rioja & 24600 & 0.33 & 0.08 \\
\hline & Total regional & 7438455 & 100.00 & 24.51 \\
\hline \multirow{5}{*}{ Cuyo } & Mendoza & 811615 & 50.66 & 2.68 \\
\hline & San Juan & 668908 & 41.76 & 2.20 \\
\hline & San Luis & 121444 & 7.58 & 0.40 \\
\hline & Total regional & 1601967 & 100.00 & 5.28 \\
\hline & Total general** & 30353185 & - & 100.00 \\
\hline
\end{tabular}

a Faltan datos sobre el primer bimestre de 1833 y el último cuatrimestre de 1835 .

* En pesos papel.

b La subregión Entre Ríos se puede dividir en dos zonas:

\begin{tabular}{llcc} 
& Monto & Porcentaje regional & $\begin{array}{c}\text { Porcentaje total } \\
\text { Paraná }\end{array}$ \\
$\begin{array}{l}\text { Costa occidental } \\
\text { río Uruguay }\end{array}$ & 3792197 & 17.79 & 12.49 \\
\hline
\end{tabular}

* Sobre un total de 5574 operaciones.

Fuente: AGN, Contribución Directa, Sala III, 23-1-9 a 23-7-6; Cargo, Sala III, 23-7-10 a 23-8-6; Cargo y Data, Sala III, 24-1-1. 


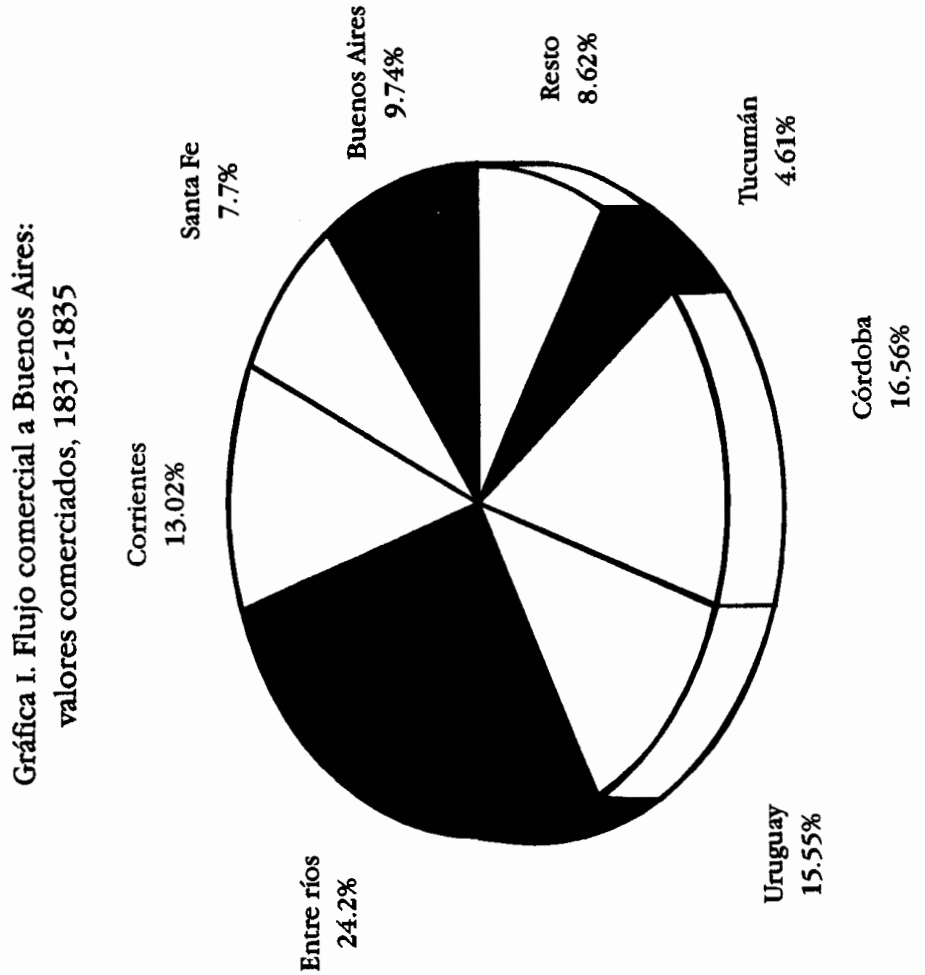


menos (9.74\%), debemos tener en cuenta que se trata de sólo una parte de la campaña bonaerense del norte, la más cercana al Paraná, por medio del cual fluye hacia la capital la producción de las zonas inmediatas a los citados puertos de San Nicolás, San Pedro, etc. Aun asi, el aporte de la misma es bastante significativo, si bien debemos asimismo tener en cuenta la labor reexportadora de los excedentes de producción del Interior que cumplieron dichos puertos.

Los porcentajes son bastante sugestivos: si bien el flujo a través del Paraná es realmente notable, no creemos que sea nada desdeñable el que aporta su hermano menor, $y$ aunque no tenemos estudios sobre periodos anteriores, lo cierto es que la costa entrerriana sobre el Uruguay se va vitalizando progresivamente, por lo que no es de extrañar la dinámica observada en el tráfico comercial a través de dicho curso de agua. Pero vayamos por partes.

Cuando tratemos el tema de la composición del flujo veremos que los productos pecuarios, especialmente los cueros, tienen la porción más significativa del monto comercial total. Podemos entonces entender el magro 7.70\% de Santa Fe:

La revolución y la guerra [...] consumicron desenfrenadamente la riqueza ganadera local. Santa Fe [...] llegó a 1820 sin ganados en sus estancias [... y] seguirá siendo, en 1830, la más aguerrida, pero la más pobre y despoblada de las provincias litoraleñas. ${ }^{26}$

26 Halperin Donghi, Revolución, 1980, p. 182. También Chiaramonte nos muestra una declinante cconomía santafesina a través de
Nuestras cifras sobre envíos de cueros a Buenos Aires confirman plenamente este descenso santafesino.

La situación de Corrientes, por el contrario, es más desahogada y no sólo por ese $13.02 \%$ del total del monto. La provincia ha experimentado a partir de 1821 una estabilidad institucional impensable en otros estados y sus gobernantes han llevado a cabo una férrea política económica basada en el proteccionismo aduanero, el fomento de la producción agrícola ganadera e industrial y la organización de un eficaz sistema rentístico, lo que desembocará en el surgimiento de una firme posición frente a Buenos Aires en las trascendentes cuestiones de la nacionalización de la aduana, la libre navegación de los ríos y, en fín, la organización constitucional del país. ${ }^{27}$

Es el turno de Entre Ríos, con similares aportes a través de los dos grandes ríos, que conforma $24.20 \%$. A diferencia de su vecina del norte, la anarquía política y el sometimiento a Buenos Aires fueron características constantes durante la década inmedia-

cifras parciales sobre sus finanzas. Véase Chiaramonte, "Finanzas", 1987, pp. 159-198.

27 Sobre el tema, puede consultarse el citado trabajo de Chiaramonte en relación con las finanzas de las provincias litoraleñas y, además, del mismo autor, "Organización", 1985, pp. 229-250, y "Legalidad", 1986, pp. 175-196. En cuanto a la cxpansión del comercio correntino hacia Buenos Aires durante la época, puede consultarse el citado estudio de Schmit. Ade más, en el caso correntino en especial, debemos tener en cuenta sus conexiones directas con la antigua Banda Oriental $c$, incluso, con Brasil, aparte de las que la ligan al resto de la confederación. 
tamente anterior al lapso que estamos estudiando. Si bien el segundo seguirá un tanto atenuado, hasta que Urquiza se sienta lo basante fuerte, la primera terminará en $1831 .{ }^{28} \mathrm{~A}$ pesar de todo, lo cierto es que a partir de nuestras cifras podemos observar que la provincia en cuestión es la que más aporta en el quinquenio estudiado, incluso si lo consideramos año por año, excepto $1832 .{ }^{29}$ En todo caso, creemos que es importante llamar la atención sobre el papel que desempeña la zona costera sobre el Uruguay, significativa ya en los primeros años de la década de $1830,3^{30}$ y que tendrá definitivo despegue al inicio de la siguiente.

En síntesis, la franja litoraleña oriental del Paraná contribuye con la cuarta parte del total de los valores comerciados hacia la aduana de Buenos Aires, mientras que la orilla de enfrente nos presenta el limitado aporte de una porción del campo bonaerense norte y una magra participación de la alicaída Santa Fe. Las imágenes de la otra vía fluvial muestran la significativa conexión comercial que existía entre la antigua Banda Oriental $^{31}$ y la capital de la confedera-

28 Sobre la situación político-cconómica de Entre Ríos pueden consultarse los ya citados trabajos de Chiaramonte, "Legalidad" y "Finanzas".

29 Véase cuadro 13, en el apéndice.

30 Para dar una idea del dinamismo de esta zona entrerriana baste decir que aporta 125775 cueros vacunos secos y salados contra 119389 que se exportan desde la orilla bañada por $\mathrm{cl}$ Paraná.

31 Probablemente hacia el final del quinquenio -asi lo indicarian las cifras-dieron resultado las medidas tomadas por Buenos Aires (reducción y eliminación de aranceles) en su ción rosista, con la dinámica que va cobrando la franja costera occidental.

De la región central sólo podemos subrayar la sustancial porción que le corresponde a Córdoba (16.56\%), segunda entre todas las subregiones en que hemos dividido el espacio. Del resto, poco hay para decir pues las cifras son por demás elocuentes: salvo por la tibia participación de Tucumán, se podría pensar que ese extenso subespacio languidece. Sin embargo, hemos anticipado que, exceptuando en cierta forma a Córdoba, gran parte de la región orientaba sus excedentes de producción hacia el mercado del altiplano, y más allá de que no tenemos cifras concretas al respecto, debemos tomar en cuenta que a partir de 1825 , cuando se reabre la ruta al Alto Perú, esta región ya ha cortado los lazos que la unían al Atlántico de la época hispánica:

El Interior será entonces para Bolivia proveedor de ganados y de alguna otra producción local; no será ya el intermediario entre el altiplano minero y Buenos Aires, emisaria de la economía metropolitana. ${ }^{32}$

"guerra entre puertos" con Montevideo, para atracr el comcrcio fluvial. Véasc Burgin, Aspectos, 1987, cap. Ix. También debería considerarse que la antigua Banda Oriental reexportaba en ocasiones productos brasileños y paraguayos; sobre el tema, puede consultarse a Niclia R. Areces y Nora E. Bouvet. "Itapúa", 1987, pp. 113-134, y Whigham, "Back-door", 1990.

32 Halpcrin Donghi, Revolución, 1972, p. 82. Cabe destacar que en el lustro inmediatamente anterior a nuestro estudio el principal destinatario de las exportaciones jujeñas es el mercado altoperuano. Véase Gamboni, "Notas", 1980, pp. 401-416. 
La situación de Cuyo, con su $5.28 \%$ en el total del flujo, es decididamente diferente de la imperante en dicha región pocos lustros atrás; la imagen que presenta a comienzos de la década de 1830 es la de una economía en crisis que sólo encuentra relativo alivio cuando logra estrechar sus vínculos comerciales con Chile. Hacia principios del lapso que estudiamos comienza en Chañarcillo un nuevo ciclo minero chileno y esa expansión del país vecino alimenta las esperanzas cuyanas. ${ }^{33} \mathrm{La}$ orientación de la región hacia el Pacífico, más allá de no poseer cifras al respecto, ${ }^{34}$ estaría probada por la aspiración de Mendoza y San Juan de reglamentar sus relaciones comerciales con Chile, que desembocará en la firma del "convenio privado" de 1835.35 No casualmente a

33 Halperin Donghi, Revolucion, 1980, pp. 289-290.

${ }^{34}$ Las pocas que hemos obtenido nos han llamado la atención, por ejemplo, las de exportación de cueros mendocinos del año 1827: de los 9 370, 670 fueron para Buenos Aires, y el resto, es decir 8700 , para Chile. Véase Parish, 1958 , p. 489.

35 Segreti, Economía, 1981, pp. 141-147. El mismo autor expresa: "Se busca el comercio con Chile porque la política porteña es la causante del general empobrecimiento y porque se ha perdido la esperanza de una próxima reorganización nacional que, mediante una constitución, pusiera lìn a tan lamentable situación. Cuando se creyó lo contrario $-y$ picnso que es la mejor prueba de mi afirmación- se buscó desalentar el comercio ultracordillerano gravándolo con un fuerte impuesto como ocurriera en 1832. Perdida toda esperanza luego de la disolución de la Comisión Répresentativa y agravada la situación económica se impone cntonces el acuerdo con Chile". Véase Scgreti, "Contribución", 1980, p. 256. También Saravi, "Consideraciones", 1980, pp. 239-253. fines de ese año, Rosas, ante la posibilidad de una desintegración del espacio económico, accede a algunos de los reclamos del Interior al establecer la famosa ley de aduanas. ${ }^{36}$

\section{Componentes del flujo}

Cueros: los cueros, especialmente los vacunos, fueron -dentro de un proceso que arrancó a fines del siglo XVIIIel principal producto exportable de estas tierras. A través del cuadro 2 se puede observar la cantidad de los mismos que desde el Interior llegó a Buenos Aires durante el quinquenio.

Si bien sería interesante, para completar el panorama, acercarnos a la cifra total de los enviados a la aduana porteña pues la diferencia estaría indicando, grosso modo, el aporte de la región casi no tratada en este trabajo, es decir la campaña bonaerense, especialmente la del sur, deberemos abandonar el análisis de la cuestión para cuando contemos con cifras de exportación suficientemente confiables, tales como las consignadas por Parish hacia el final del periodo rosista. Volveremos sobre el tema.

Consideraremos ahora diversos aspectos que surgen del envío de cueros vacunos desde algunas regiones del Interior. A través de la curva dibujada por Assadourian ${ }^{37}$ parecería que el número de cueros vacunos cordobeses exportados a Buenos Aires es más alto que el registrado por nosotros (excep-

36 Halperin Donghi, Revolucion, 1972, p. 83.

37 Assadourian, "Scetor", p. 323; la información fue extraída de la aduana de Córdoba. 


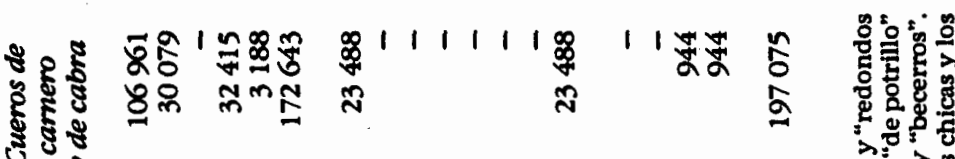

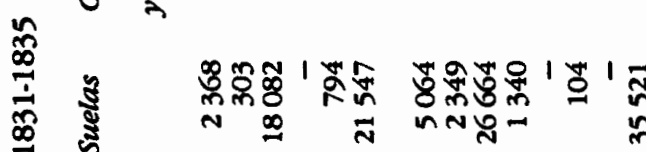

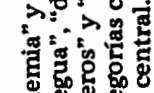
$8 \quad 8$ in

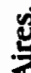

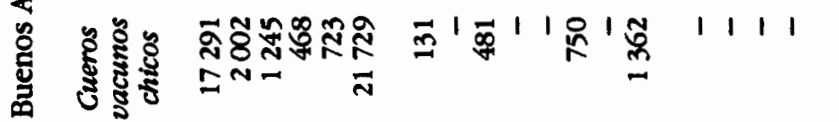

ซ

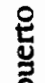

है :

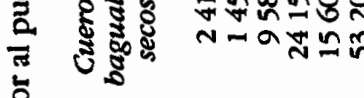

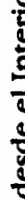

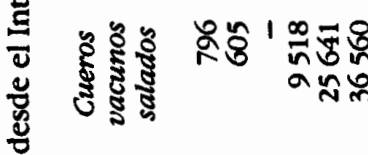

总

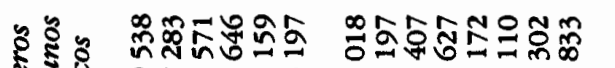

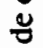

ㅇํำ 路

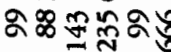

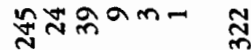

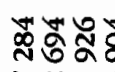

$\overline{8}$

$\because 0$.

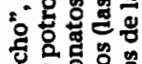

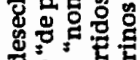

N

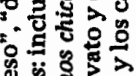

웡 है형

\%

*

in 5050

ㅇํㅇ

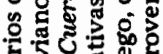

8 政

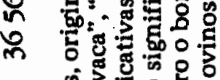

कै?

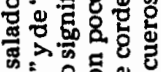

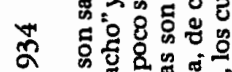

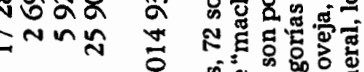

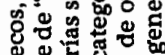

\%

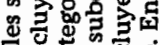

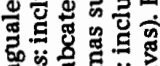

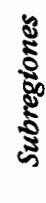

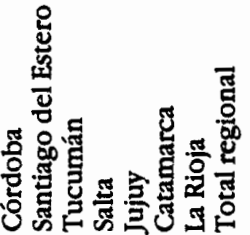

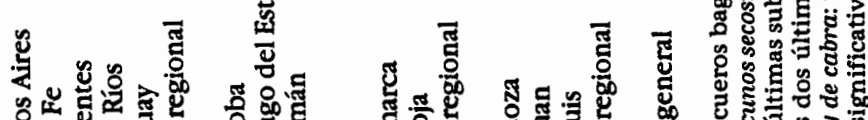

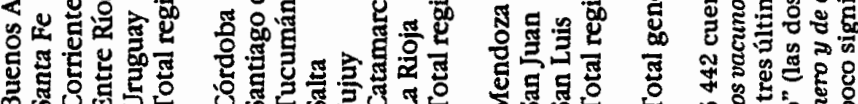

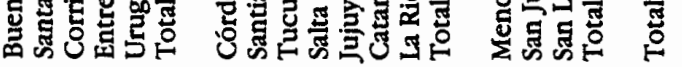

宽

胥

క్ తి

is

원

- 


\section{SECUENCIA}

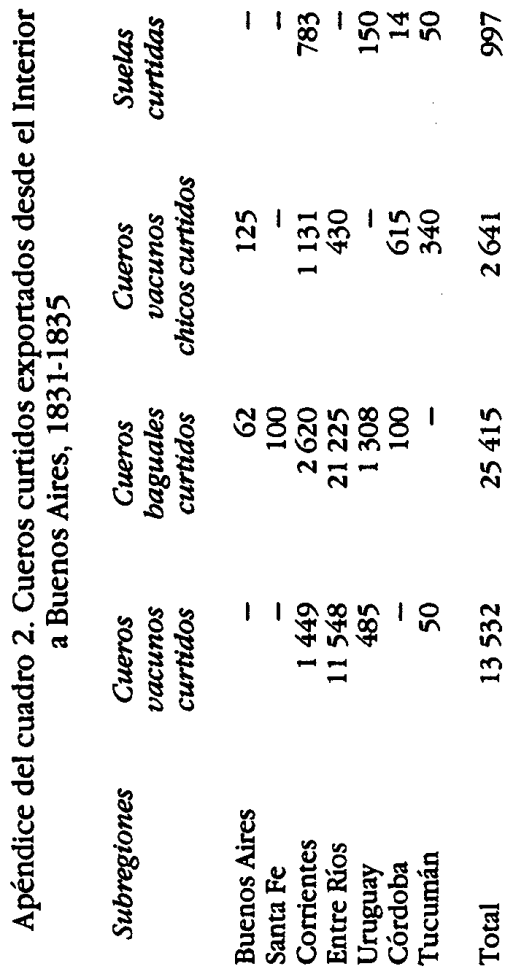




\section{SECUENCIA}

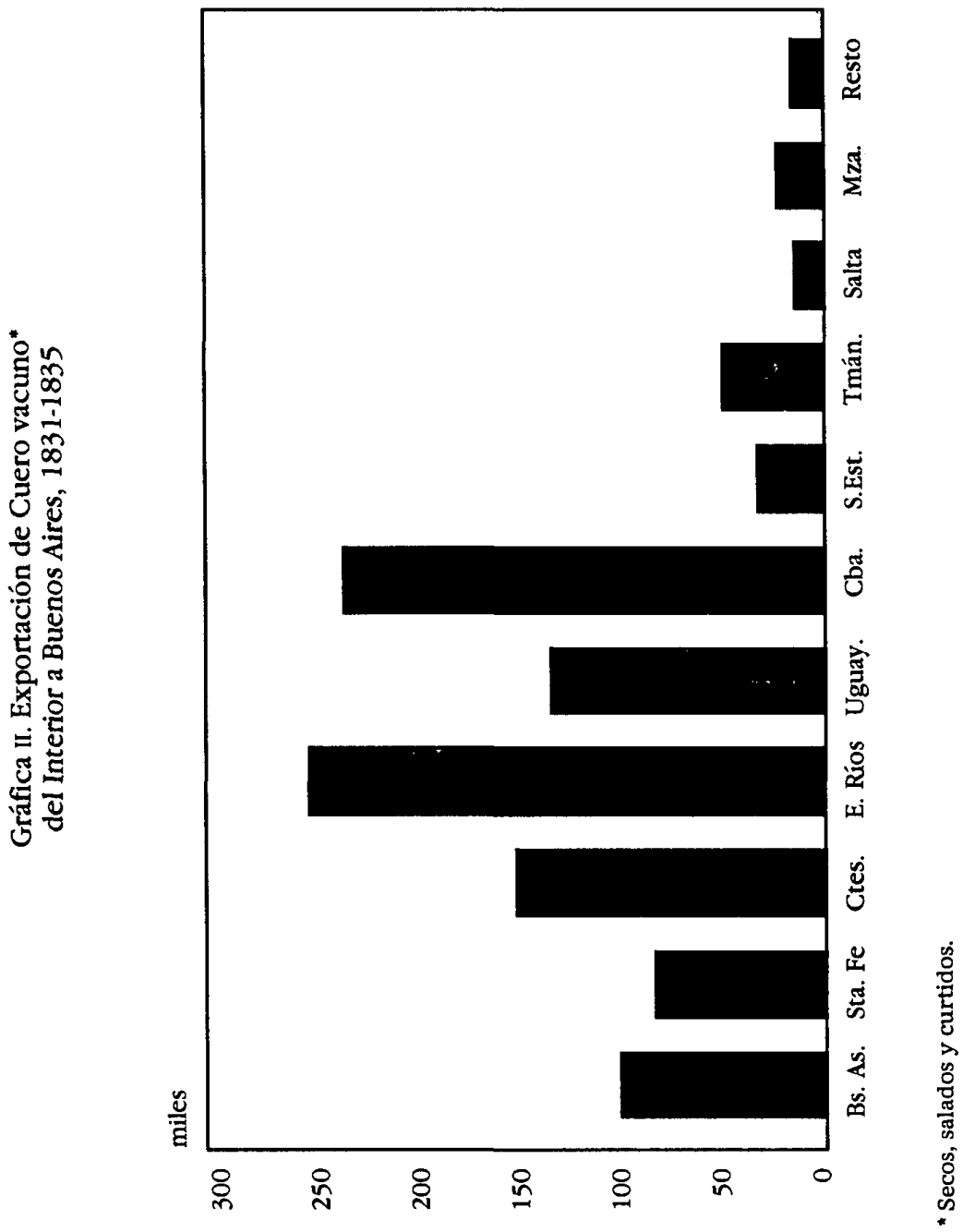




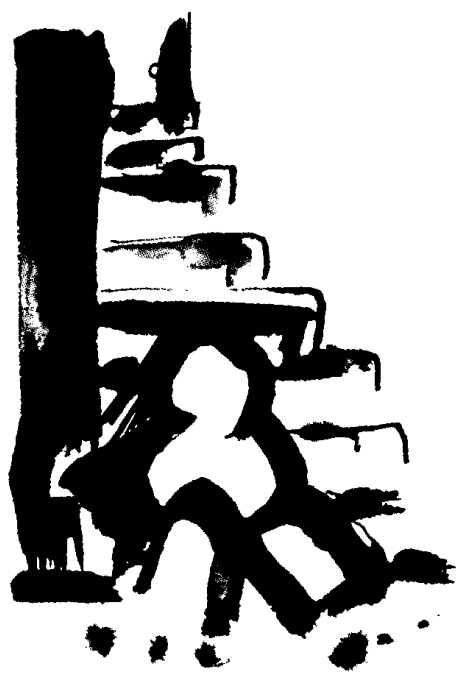

to para el año 1832). Esto podría deberse a varias causas. En principio se debe tener en cuenta la pérdida de documentación (nosotros no hemos podido hallar la correspondiente al primer bimestre de 1833 y nos falta la del último cuatrimestre de 1835). Es posible que mercancías salidas desde Córdoba hacia el puerto no llegaran a destino a causa de la convulsión interna que sufrió el país en aquellos años. ${ }^{38} \mathrm{Y}$ además están las evasiones fiscales. Halperin Donghi, refiriéndose a la década de 1820 , habla de "cueros de animales sacrificados en la campaña [de Buenos Aires] y exportados sin pasar por los mercados", 39 y el

38 Ibid., p. 335 .

39 Halperin Donghi, Revolucion, 1980, pp. 289-290.

EL INTERIOR FRENTE A BUENOS AIRES mismo Assadourian comenta los embarques en otros puertos, por ejem-plo Santa Fe, hacia la época del segundo bloqueo europeo: en 1847 "los comerciantes cordobeses envían 11613 cueros a Buenos Aires y 26491 hacia Santa Fe, lugar donde las circunstancias políticas permitían evadir el bloqueo impuesto al puerto principal del país" (y agrega que algo similar hacía Urquiza en Entre Ríos); ${ }^{40} \mathrm{sin}$ embargo, Assadourian coloca en su curva a poco más de 38000 cueros como enviados a Buenos Aires. También Giberti hace alusión, para 1829 , a "deficiencias estadísticas" y "evasión de impuestos" al referirse al sacrificio de animales vacunos destinados ${ }^{40}$ Assadourian, "Sector", 1983, p. 235. 
a los saladeros porteños. ${ }^{41}$ En fin, es probable que situaciones semejantes se hayan dado durante la época que estamos estudiando. Y en todo caso, la pérdida de documentación y de mercancías, la imperfección en las estadisticas y la evasión fiscal, todas o algunas de estas causas, explicarían la disimilitud entre nuestras cifras y las de Assadourian.

También con Roberto Schmit tenemos algunas diferencias; al estudiar el comercio correntino hacia Buenos Aires entre 1822 y 1833 , obtiene registros más altos que los nuestros en el caso de los envíos de cueros vacunos, y más bajos en lo que se refiere a las remesas de cueros baguales, entre los años 1831 y 1833 , únicos que pudimos comparar. De todos modos, las diferencias no son significativas y se pueden entender por el hecho de haberse utilizado en las respectivas investigaciones distinto tipo de fuentes. ${ }^{42}$ En cualquier caso, de los casi 12000 cueros baguales que según nuestras cifras exportó Corrientes a Buenos Aires entre 1831 y 1835 , más de 8500 corresponden al primero de los años citados. Es posible que luego de ese año se haya dado una situación similar a la planteada por Burgin, es decir la fijación por parte del gobierno provincial de "un impuesto relativamente elevado a la exportación de cueros de caballo [lo cual tenía] por

41 Giberti, Historia, 1985 , p. 88.

42 Schmit, "Mercados", 1991. pp. 57-60. A nuestro entender, Schmit pudo manejar una fuente más precisa que la nuestra en lo que sc refiere al origen de los cargamentos; también en lo referente a las suelas tenemos disimilitud en las cifras. objeto impedir la matanza en gran escala de los equinos", y enseguida agrega que "a veces se prohibia totalmente la exportación de ganado vacuno o de caballo en pie [para] evitar el agotamiento de los recursos naturales".43

Teniendo en cuenta el valor de los cueros se puede vislumbrar la significativa porción que ocupan dentro del monto comerciado total: $61.24 \%$; si bien este porcentaje engloba a los cueros vacunos, baguales, ovinos y caprinos, los primeros son los que en buena parte la conforman $\mathbf{5 2 . 8 7 \%}$ de dicho monto) (véase cuadro 18 en el apéndice).

De todos modos, es conveniente hacer algunas aclaraciones respecto a estas cifras. Obviamente, hemos utilizado "precios" de aforo. Los mismos se mantuvieron estables durante el quinquenio, aunque con leves variaciones, ${ }^{44}$ lo que nos llevó a establecer precios promedio. Sin embargo, la mayor dificultad estuvo dada por los pocos ejemplos encontrados para algunas categorias, y si bien afortunadamente éstas eran las menos significativas, debimos fijar precios tentativos. ${ }^{45}$ No obstante lo apuntado, esti-

43 Burgin, Aspectos, 1987 , p. 183. Además, se debe recordar la finalidad militar de los animales caballares.

${ }^{44}$ A pesar de todas las diticultades fìnancieras de la provincia de Buenos Aires, el estudio de $M$. Burgin cstablece que "el valor del peso papel permaneció en verdad relativamente estable durante toda la primera mitad del decenio del 30". Véasc Burgin, Aspectos, 1987, p. 219.

45 Para dar una idea sobre el tema, digamos que los cueros vacunos secos, el grueso del total aquí analizado, costaba unos 15 pesos papel, y 17 y 18 pesos los salados y curticlos, respectivamente. Los cucros chicos valian en- 
mamos que los valores manejados se acercan bastante a la realidad, una realidad que ilustra acerca del predominio de la actividad pecuaria en estas tierras, sin duda potenciado por un vigoroso mercado externo. ${ }^{46}$

tre 2 y 3 pesos y los caballares andaban en los 9 pesos los secos y 12 los curtidos, mientras que los ovinos y caprinos valian alrededor de un peso. En tanto, las suelas podían alcanzar los 30 , c incluso más. También debemos tener en cuenta que no todos los cueros que llegaron a la aduana porteña pagaron contribución directa; los llegados hacia fines de 1835 (alrededor de 8000 cueros vacunos, 500 baguales y 800 suelas), al no haber sido considerados en los cuadros de los montos tampoco se los contempló en el de valores. Sobre el tema de los "precios" puede consultarse a Broide, Evolucion, 1951. Para el caso de los cueros vacunos, el autor se refiere a "la pesada de cueros de 35 libras y la mejor calidad de cueros de buey", y no a unidades, tal como aparecen en nuestros cuadros y en donde se engloban distintas calidades (de macho, de vaca, de desecho, etc.), por lo que no es posible utilizar la serie; algo similar le sucedió a Chiaramonte, Mercaderes, 1991, p. 245. Para el caso del precio de los cueros de caballo, por el contrario, la serie está elaborada con base en pesos papel por unidad; a través de la misma hemos calculado un precio promedio general del quinquenio de 9.80 , bastante cercano al obtenido por nosotros, que fue de 9 pesos.

46 "A lo largo de la primera mitad del siglo XIX los cueros nunca constituyeron menos de 60\% del total de exportaciones en valor; muy frecuentemente proporcionaron más de $70 \%$ de ese total. El resto estaba constituido en buena parte por exportaciones complementarias de las de cuero: otros productos de la industrialización del vacuno, básicamente carne salada y sebo (pero también por valores mucho menores, astas, huesos para botones y para abono, crin, etc.) completan hasta medidados de la década del 40, alrededor de $90 \%$ del valor total de las exportaciones." Halperin Donghi, "Expansión", 1963, p. 59.
Tejidos "de la tierra": si bien la producción textil del Interior había comenzado a decaer a partir de fines del periodo colonial, la presencia de los tejidos cordobeses y santiagueños en Buenos Aires - que sin duda configuraba el mercado consumidor y el centro redistribuidor más importante que tenían los mismos en el espacio rioplatense- era aún considerable en la temprana etapa rosista. ${ }^{47}$ Debemos aclarar, sin embargo, que nos estamos refiriendo al aspecto numérico de la cuestión (cantidad de "piezas"), pues si hablamos en términos de "valor", el de los tejidos era bastante exiguo, especialmente si lo comparamos con el de los cueros vacunos. ${ }^{48}$

Una clasificación muy general de los tejidos coloniales nos indica que existían los de lana, los de algodón y los mixtos. Los primeros estaban representados mayoritariamente por los ponchos y "frezadas", pero incluían

47 Sobre los textiles de la tierra, su producción y circulación dentro del espacio en estudio, puede consultarse, entre otros, el trabajo de Garavaglia y Wentzel, "Nuevo", 1990, pp. $211,241$.

${ }^{48}$ El precio de aforo de ponchos y jergas de Córdoba giraba, para el quinquenio en estudio, alrededor de los 4 pesos; sobre los ponchos santiagüeños no hemos obtenido datos, aunque probablemente fueran un poco más caros. Tal como expresan Garavaglia y Wentzel, entre 1802 y 1821 "el valor total de los textiles del área del poncho no ocupa sino un rol muy secundario en el mercado de Buenos Aires". Véase Garavaglia y Wentzel, "Nuevo", 1990, p. 215. Para la época que estamos tratando, este proceso se había acentuado, pues se daba, por un lado, una menor presencia numérica y, por otro, la alta valuación que había alcanzado los productos pecuarios, en especial los cueros. 
también los cortes de jergas, bayeta, picote, etc., provenientes de Córdoba y San Luis; otros textiles de lana eran originarios del Perú, Alto Perú y Chile; por último, sabemos que en el mercado porteño tenían una considerable receptividad los ponchos y jergas pampas, producidos por las tribus araucanizadas. Los lienzos de las $\mathrm{Mi}$ siones, los catamarqueños y los tucuyos cochabambinos estaban confeccionados, a su vez, de algodón. Los textiles mixtos, por su parte, tenían en los ponchos santiagueños los representantes típicos (aunque los había del mismo origen realizados en lana). ${ }^{49}$

Las piezas textiles que hemos de considerar en este trabajo -y que han sido agrupadas por Garavaglia y Wentzel bajo la denominación de "textiles del área del poncho" -serían entonces los ponchos "llanos" cordobeses, de lana, sencillos en su confección y de bajo costo; los santiagueños, que tenian una mayor elaboración, sugestivos diseños y llamativas tonalidades y que eran por supuesto de un precio más alto; las "frezadas" (y "frezadones") y jergas (y jergones). Las fuentes también nos hablan de "piezas de tejidos del país", originarias de Córdoba: son fardos que incluyen indistintamente ponchos, "frezadas", jergas, cortes de bayeta y de picote, etc., sin especificar cantidades, por lo que las hemos reunido en un grupo aparte en el cuadro respectivo.

En el cuadro 3 se puede observar el número de piezas de tejidos "de la tierra" llegadas a Buenos Aires entre

49 lbid., pp. 215-218.
1831 y $1835,{ }^{50}$ con un promedio de unas 37830 unidades por año (aunque con marcadas variaciones anuales, las cuales pueden tener su explicación, en parte, en las convulsiones internas que sufrió la región). Si cotejamos nuestras cifras con algunas de las consignadas por Garavaglia $y$ Wentzel, ${ }^{51}$ veremos que están lejos de las obtenidas por éstos para los periodos $1800-09$ ( 87840 piezas anuales en promedio), 1810-14 (55 747), $1815-21$ (56 246), pero que a su vez superan a las del lapso 1840-45 (34 803). Es decir que, aparentemente, se va confirmando ese lento (pero irreversible) retroceso de la presencia textil cordobesa y santiagueña en la aduana de Buenos Aires señalado por los citados autores. Y aquí hay que recordar que si estos textiles pudieron resistir la competencia de los tejidos europeos se debió al bajo costo de su producción, merced a la "autoexplotación de la fuerza de trabajo familiar en el marco de la economía campesina" y, en parte, a razones relacionadas con la moda que hicieron que se llegara a preferir tejidos de más baja calidad pero vistosos. ${ }^{52}$ Es posible que estas causas de indole económica y sociológica fueran más efectivas que el presunto proteccionismo de la tan mentada Ley de Aduanas, la cual, según Garavaglia y Wentzel, "no parece haber tenido sino

So Recordemos que nos faltan datos sobre el primer bimestre de 18.33 y el último cuatrimestre de 1835 .

51 Garavaglia y Wentzel, "Nuevo", 1990, cuadro 4 , p. 228.

52 Ibid., p. 235. Halperin Donghi, Revolucion, 1972, pp. 106-107. 


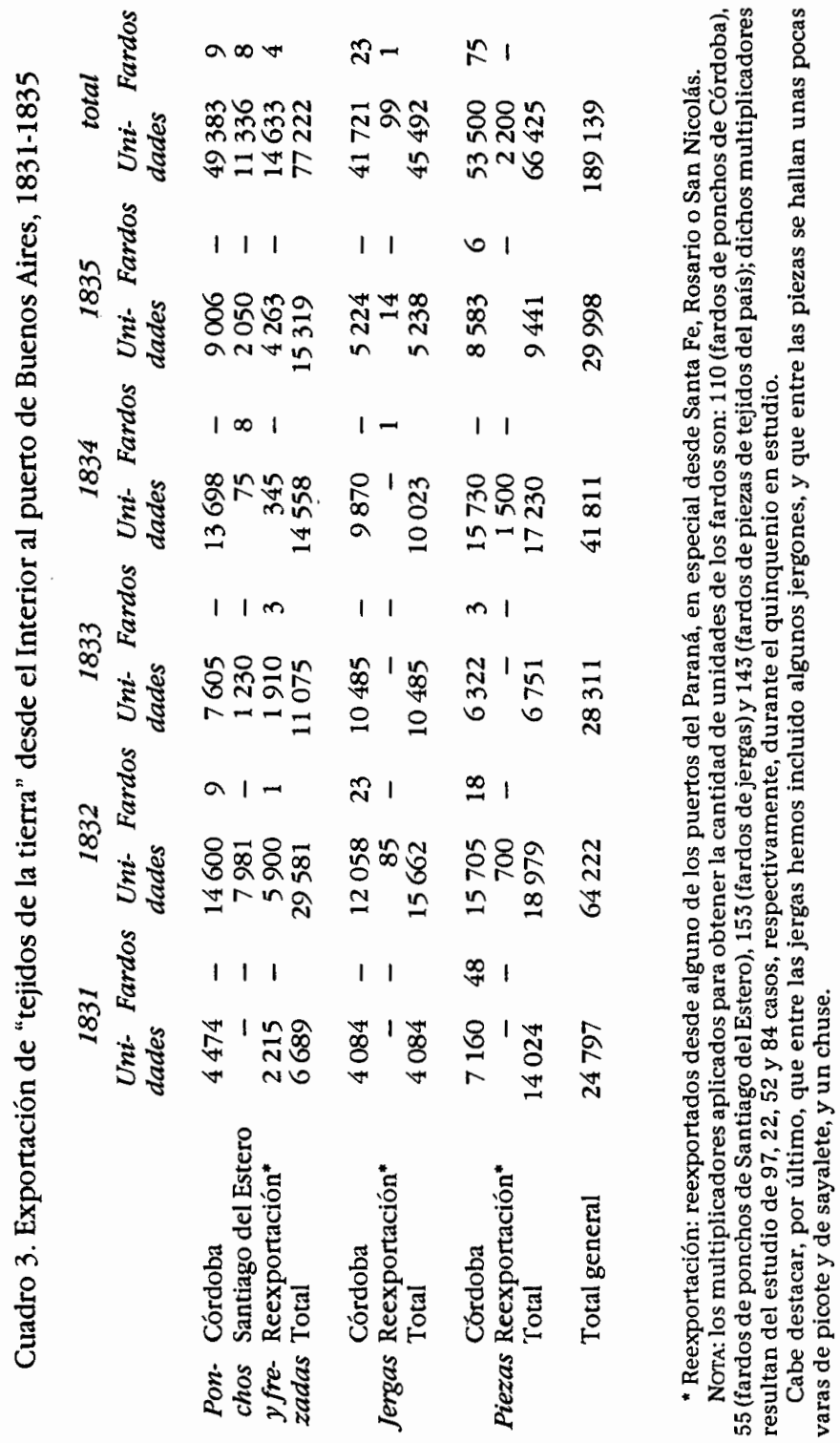


Cuadro 4. Exportación de "caldos de la tierra" cuyanos al puerto de Buenos Aires, 1831-1835 (en arrobas)

Aguardiente

Vino

\begin{tabular}{|c|c|c|c|c|c|c|}
\hline Mendoza & $\begin{array}{l}\text { San } \\
\text { Juan }\end{array}$ & $\begin{array}{c}\text { Reex- } \\
\text { porta- } \\
\text { dos* }\end{array}$ & Total & Mendoza & $\begin{array}{c}\text { San } \\
\text { Juan }\end{array}$ & $\begin{array}{c}\text { Reex- } \\
\text { porta- } \\
\text { dos* }\end{array}$ \\
\hline
\end{tabular}

$\begin{array}{rrrrrrrrr}1831 & 200 & 2348 & 610 & 3158 & 164 & 8 & 24 & 196 \\ 1832 & 32 & 4256 & 314 & 4602 & 658 & 494 & 46 & 198 \\ 1833 & 374 & 3394 & 64 & 3832 & 516 & 80 & - & 596 \\ 1834 & 762 & 832 & - & 1594 & 60 & 52 & - & 112 \\ 1835 & 84 & 366 & 32 & 482 & - & - & - & - \\ \text { Total } & 1452 & 11196 & 1020 & 13668 & 1398 & 634 & 70 & 2102\end{array}$

*Reexportados: desde alguno de los puertos del Paraná, en especial desde Santa Fe, Rosario o San Nicolás.

escasa influencia en la evolución de la producción textil campesina durante el periodo $1830-1850^{\prime \prime} .53$

Caldos "de la tierra": un rápido vistazo al cuadro 4 nos permitirá comprender que la otrora floreciente producción vitivinícola cuyana, en el contexto de las relaciones de producción coloniales, era en la década de 1830 una .cosa del pasado. (Sólo a fines del siglo la región tendrá un nuevo periodo de desarrollo de la industria en cuestión, pero ese es tema de otro estudio.) En esta crisis cuyana mucho tendrán que ver la competencia de los caldos extranjeros y los estragos de la guerra civil. Las vides ahora son reemplazadas por los alfalfares, que no sólo alimentan a los ganados locales sino también a los de las 239.

53 Garavaglia y Wentzel, "Nucvo", 1990, p. provincias centrales que se orientan hacia el mercado del Pacífico. ${ }^{54}$

De las arrobas de aguardiente y vino llegadas a Buenos Aires, obtenemos como promedio del periodo unas 2734 y 420 arrobas anuales, respectivamente. ${ }^{55}$ Comparando estas cifras con las del quinquenio 1817-21 -lapso al final del cual ya era evidente la crisis de la economía cuyana-, cuando se alcanzaron como media anual alrededor de 15650 arrobas de aguardiente y 27175 de vino, 56 notamos que si bien la caída de la exportación 290.

S4 Halperin Donghi, Revolucion, 1980, p.

55 Una vez más debemos recordar que nos faltan datos sobre el primer bicmestre de 1833 $y$ el último cuatrimestre de 1835 .

56 Los promedios fueron obtenidos de los datos extraidos de la tabla confeccionada por Claudia Wentzel, "Buenos Aires. Importación de caldos cuyanos, 1802-1821", a su vez inserta en el trabajo de Amaral, "Comercio", 1990, p. 51. 
de caldos desde Cuyo a Buenos Aires fue significativa en el caso del aguardiente, fue decididamente espectacular en el del vino. 57

Y una manifestación más de esta declinación cuyana. Si toda la carga de San Juan y Mendoza -cueros, caldos y frutas secas, principalmente- se hubiera trasladado en carretas, se habrian necesitado unas 1000 unidades, es decir unas 200 por año como promedio, bastante alejado de la media alcanzada en el periodo 1781-1811 que era alrededor de 635 vehículos (y eso sin contar el considerable acarreo de las mulas -unas 1845 como promedio- que de enero a diciembre llegaban al mercado porteño en dicho lapso). ${ }^{58}$ Sin embargo, la realidad del

57 En el año 1827 se transportaron desde Mendoza a Buenos Aires 12608 arrobas de aguardiente y 15960 arrobas de vino. Véase Parish, Buenos Aires, 1958, p. 489. Esta signifcativa cantidad de una de las dos provincias productoras se entiende, pues Buenos Aires sufría en esos momentos el bloqueo brasileño. (Si fijamos nuestra atención en la cita de la nota 34 entenderemos por qué Mendoza debía enviar sus cucros a Chile: en Buenos Aires, los cueros sobraban, en cambio los caldos...).

58 Rosal, "Transportes", 1989. Los promedios se obtuvieron de los datos aparecidos en la p. 151, que incluyen vehículos y bestias movilizados desde San Luis y Río Cuarto, los que en realidad conforman un número bastante poco significativo; en ese sentido fue más importante el desplazamiento de carretas mendocinas que generó la carga originaria de Chile, transportada a través de los Andes. En 1820, cuando la decadencia del comercio cuyano era una realidad palpable, se trasladaron desde la región aproximadamente 160 carretas y 3290 mulas. Véase Rosal, "Transportes", 1990, pp. 15-25. Sobre la crisis del comercio cuyano, también puede consultarse la citada obra de Amaral, "Comercio", 1990. periodo 1831-1835 era más cruda aún, pues lo concreto es que buena parte de los productos mendocinos y casi la totalidad de los de San Juan se desplazaron en mulas, lo que refleja el estancamiento e incluso la decadencia del transporte carretil.

Otros: En este rubro se han considerado siete productos que, en distintos lapsos y para algunas de las subregiones, han tenido un peso más o menos significativo en la conformación de los respectivos flujos mercantiles. En el Apéndice se puede apreciar, a través del cuadro 15 , el volumen de dichas mercancías; alli se destacan el tasajo oriental y la lana, tanto litoraleña como cordobesa, cuyos precios para el periodo eran alrededor de 12 pesos el quintal y 10 pesos la arroba, respectivamente. $\mathrm{Pa}$ ra los demás productos los precios son demasiado fluctuantes como para sacar alguna conclusión, o directamente se ignoran.

\section{Observaciones finales sobre el lapso 1831-1835}

El precedente análisis sobre la articulación del espacio rioplatense con Buenos Aires durante la temprana edad rosista tiene dos dificultades de considerable significación: en primer lugar, se trata de un corto lapso; en segundo, las fuentes utilizadas son incompletas. Por lo tanto, las conclusiones -si podemos llamarlas así- a que hemos arribado no pueden ser sino limitadas y provisionales.

De este modo, el estudio de los flujos comerciales desde el Interior 
hacia el principal puerto exportador de la confederación rosista durante el quinquenio 1831-1835 refleja el lugar preponderante que ocupa la tegión litoraleña -incluida una pequeña zona de la campaña bonaerense del norte, inmediata a los puertos que se erigieron a lo largo del Paraná- en la composición total del monto de los valores comerciados.

Dentro de la región podemos destacar el papel que cumple Entre Ríos, la cual posee una significativa porción - casi la cuarta parte- de la totalidad de dicho monto ( $y$ en donde va adquiriendo una dinámica propia la franja costera sobre el Uruguay), beneficiada sin duda por el fin de la anarquía política que la había desgastado durante toda la década anterior.

Corrientes, con un considerable aporte, ha experimentado desde 1821 una saludable estabilidad institucional que permitió el establecimiento de una férrea política económica al servicio de la provincia y el fomento de firmes convicciones federalistas que tarde o temprano chocarán con los intereses bonaerenses.

La otra gran provincia litoraleña, Santa Fe, por el contrario, muestra la imagen de una economía estancada; las guerras civiles han consumido su principal riqueza, el ganado vacuno, $y$ los santafesinos no han podido reponerse.

Buenos Aires cumple un modesto papel (en el cual coadyuva la labor reexportadora de parte de los productos, ya sea de las provincias interiores, ya de las del Litoral, que desempeñan algunos de sus puertos, en especial San Nicolás) en tanto se trata de una pequeña zona de la campaña bonaerense del norte.

Por último, nuestros datos confirman la significativa conexión comercial que perduraba entre la antigua Banda Oriental y Buenos Aires.

Del resto del espacio rioplatense, podemos destacar la pujanza de Córdoba -segunda subregión en importancia si consideramos la totalidad del monto comerciado- y poco más. Las economías del Interior parecen más comprometidas y, en todo caso, sus lazos con el puerto son débiles, por momentos inexistentes; la búsqueda de salidas alternativas para sus productos pone en evidencia la posibilidad de una fragmentación del espacio económico, lo cual arrancará algunas concesiones del poder portuario, tal es el caso de la Ley de Aduanas de 1835.

La actividad productiva por excelencia es la pecuaria, cuyo destino casi exclusivo es el mercado externo, y tiene en los cueros vacunos secos el bien más preciado, ya que significan más de $50 \%$ del monto comerciado total.

En otro orden de cosas, cabe destacar la persistente presencia de los tejidos "de la tierra" -aparentemente en una lenta y progresiva desaparición de la plaza de Buenos Aires- merced a sus bajos costos de producción y, en parte, a sus diseños llamativos que los hicieron competitivos frente a los productos europeos.

En cuanto a los caldos "de la tierra" originarios de Cuyo, hemos notado la vertiginosa caída en la introducción de los mismos -especialmente en el caso del vino- en el mercado porte- 


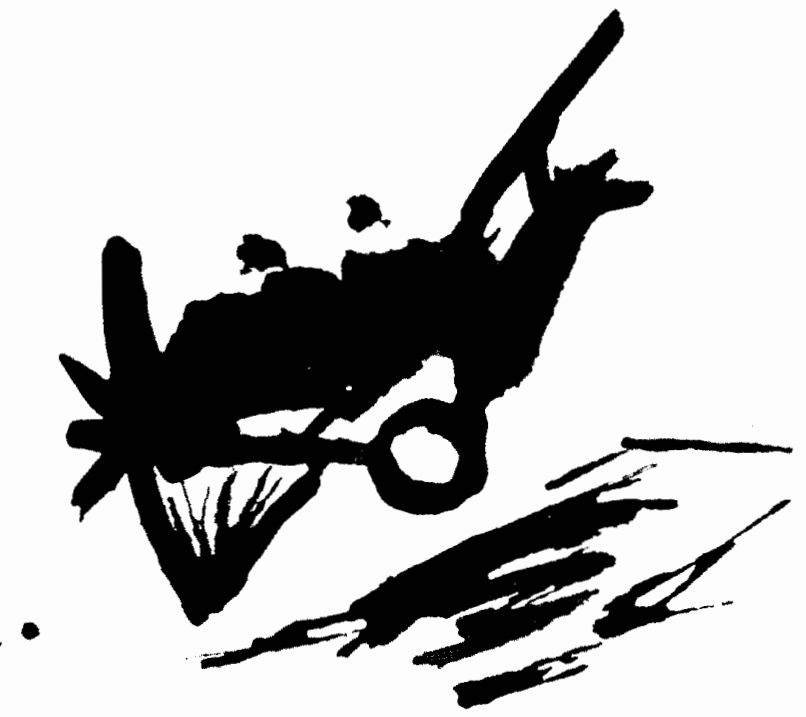

ño, lo cual refleja la crisis de las economías de Mendoza y San Juan, producto tanto de la competencia de los caldos extranjeros como de los estragos que produjo la guerra civil.

Por último, entre los restantes flujos secundarios, se destacan los envíos de la lana litoraleña y cordobesa, así como los del tasajo de la antigua Banda Oriental.

\section{LAPSO $1836-1838$}

El tratamiento del tema de los flujos mercantiles desde el Interior a Buenos Aires cuenta para este corto periodo con varias dificultades. En principio, las fuentes son incompletas pues nos falta la información del primer semes- tre de 1836; en segundo lugar, los datos utilizables no están desagregados en forma regional; finalmente, el año 1838 sufrirá las consecuencias de la distorsión provocada por el comienzo del bloqueo francés. En síntesis, si bien el margen para el análisis que ofrece no es muy prometedor, es importante acercarnos al problema que nos ocupa, incluso a través de una fuente no demasiado generosa, para tratar de vislumbrar la respuesta del Interior a la Ley de Aduanas de fines de 1835.

Dadas las dificultades mencionadas, 1837 podría tomarse como año base para el análisis en cuestión.

Los dos semestres que lo conforman -según la presentación de los datos efectuados por el Registro Ofi- 
cial de la Provincia de Buenos Airesalcanzaron montos comerciados muy similares. Parece posible que algo semejante haya sucedido en 1836 . De ser correcta nuestra presunción, ambos serian los más importantes de la década y estarian mostrando un efecto inmediato favorable por parte de las provincias a la política arancelaria aplicada a través de la citada ley.

Cuadro 5. Flujo comercial hacia

Buenos Aires: total de valores comerciados, 1836-1838

Año

$1836^{2}$

1837

1838

Total

\section{Monto*}

7887751 ps. 2 rls. 15385273 ps. 2 ris. 8954031 ps. 3 rls.

$$
32227055 \text { ps. } 7 \text { rls. }
$$

* En pesos papel.

a Faltan datos sobre el primer semestre.

FuENTE: Registro Oficial de la Provincia de Buenos Aires, años 1837, 1838 y 1839.

Dentro de los componentes del flujo, podemos apreciar, una vez más, el destacado lugar que ocupan los cueros.

Haciendo comparaciones con el lapso anterior vemos que los cueros vacunos secos suman más de la mitad de los llegados entre 1831 y 1835 , y los salados directamente los superan. Si bien no se consignan cueros vacunos curtidos y es bajo el número de los chicos, es importante la cantidad de suelas $y$ de los chicos curtidos, siendo diferente la situación en el rubro de los cueros caballares. Sin embargo, el salto más significativo se da en los cueros ovinos y caprinos. Al respecto, los lanares adquirirán importancia en momentos de tranquilidad social, para perderla rápidamente cuando las guerras civiles impidan las tareas rurales [...] Comienza en 1836 una breve época de paz que alienta a los criadores. 59

Los envíos de lana de este lapso (véase Apéndice, cuadro 16) parecerian confirmar estas apreciaciones.

En cuanto a la porción que ocupan los cueros en el monto comerciado total, sufre una considerable merma, a pesar de que su precio tiende a subir. ${ }^{60}$ Es posible que tanto la inflación como cierta diversificación de la producción de las provincias y envío de la misma al puerto como respuesta favorable a la Ley de Aduanas, sean la explicación a este fenómeno. Además, para el caso particular de 1838 , sin duda tuvo mucho que ver la distorsión causada por el bloqueo.

También las remesas de tejidos y caldos "de la tierra", especialmente en el caso de los primeros, invitan a pensar en una favorable reacción por parte del Interior ante la Ley de Aduanas.

En cuanto a los textiles, una vez más debemos aclarar que en todo caso se trata de una cuestión de cantidad, pues si nos fijáramos en el valor de estos productos veríamos que la porción que ocupan en el monto comerciado total oscila entre 2 y 5\%. Sin

59 Giberti, Historta, 1985, p. 107.

60 El precio por unidad de los cueros vacunos secos es de aproximadamente 18, 17 y 20 pesos para 1836,1837 y 1838 , respectivamente. La porción que ocupan -tanto los cueros vacunos como los cueros en general- en el monto comerciado total puede apreciarse en el Apéndice, cuadro 18. 


\section{SECUENCIA}

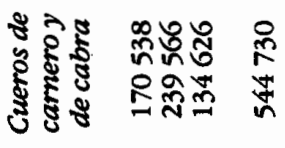

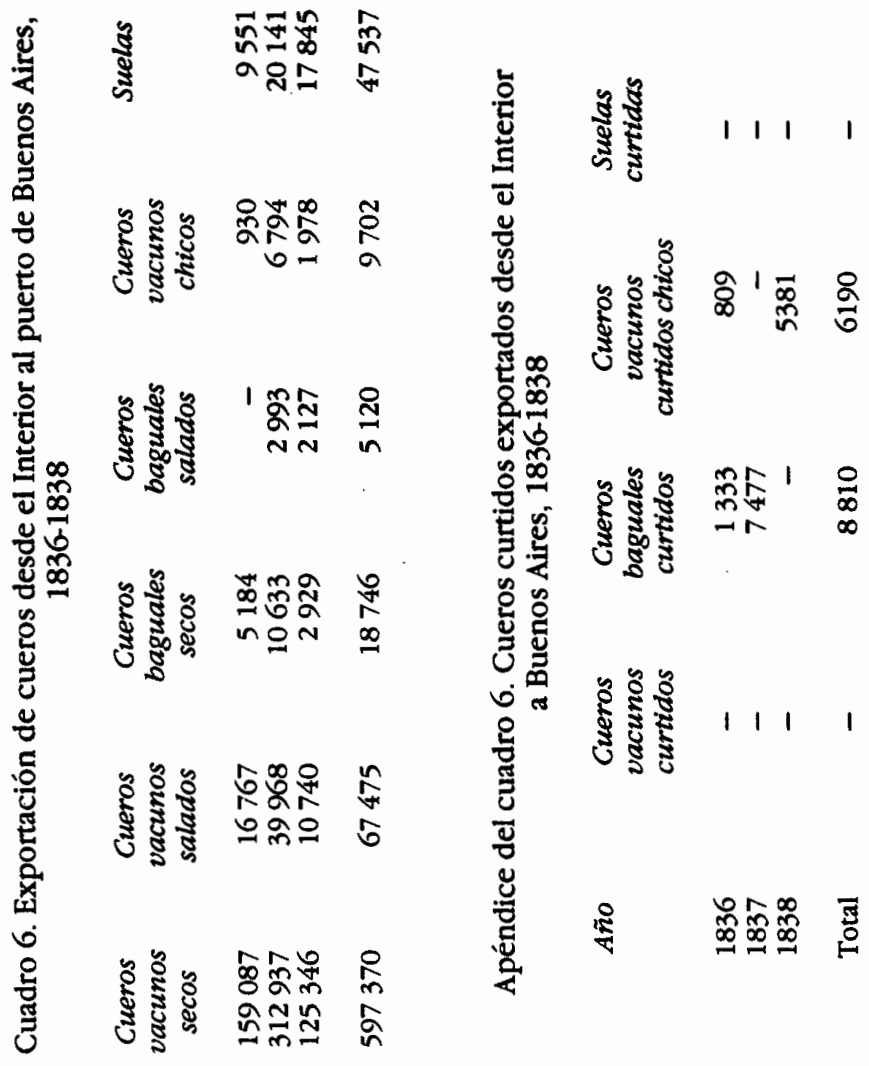

家 $\quad$ 
Cuadro 7. Exportación de "tejidos de la tierra" desde el Interior al puerto de Buenos Aires, 1836-1838

$\begin{array}{rrrrrr}\text { Año } & \text { Ponchos } & \text { Frazadas } & \text { Jergas } & \text { Piezas } & \text { Total } \\ & & & & & \\ 1836 & 6223 & 3489 & 15556 & 16159 & 41427 \\ 1837 & 35335 & 45396 & 39606 & 8723 & 129060 \\ 1838 & 28720 & 25799 & 36833 & 34 & 91386 \\ \text { Total } & 70278 & 74684 & 91995 & 24916 & 261873\end{array}$

Nota: las piezas de 1836 y 1837 corresponden a 113 y 61 fardos, respectivamente; se aplicó el multiplicador "143" obtenido para el periodo 1831-1835. Las piezas de 1838 incluyen sayales y bayetones.

Las frazadas incluyen "frezadones" y las jergas, jergones.

embargo, no podemos pasar por alto las 87291 piezas que como promedio entraron en el lapso en cuestión, ${ }^{61}$ una media casi igual a la que se dio entre 1800 y 1809 , que, según datos de Garavaglia y Wentzel, fue el periodo de mayor penetración de los tejidos "de la tierra" en el mercado de Buenos Aires. ${ }^{62}$

Cuadro 8. Exportación de "caldos de la tierra" del Interior al puerto de Buenos Aires, 1836-1838*

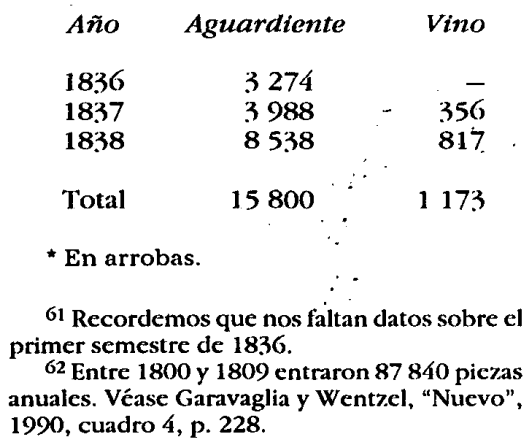

También fue significativa, para el periodo que estamos tratando, la cantidad de arrobas de aguardiente que llegó a la aduana porteña. El caso del vino "de la tierra", sin embargo, parece insoluble. En cuanto a la porción que les corresponde en el monto comerciado total, es similar a la de los textiles: oscila entre 1 y $6 \%$.

En fin, otros rubros que tuvieron un significativo crecimiento en sus envíos fueron el tasajo, la harina $y$ cordobanes.

Cabría preguntarse, por último, cuál es el valor real de estas cifras, teniendo en cuenta las características de la fuente de donde fueron extraídas y las de aquella en la cual se basó la mayor parte del presente trabajo. Como anticipamos, el Registro Oficial consigna datos a partir del segundo semestre de 1835 (aunque son utilizables sólo desde el segundo de 1836) y hasta el primero de 1840. De allí que la mejor opción que nos queda para comparar la información del Registro con la extraída de la Contribución Directa es elegir el año 1839 , al que sólo 
le faltan los datos del primer cuatrimestre de la segunda de las mencionadas fuentes. El cruzamiento de cifras efectuado nos permite decir que, en términos generales, ambas consignan la misma información, lo cual daría margen para afirmar que, más allá de la falta de desagregación regional del Registro, éste coadyuva en una forma relativamente eficaz a solucionar los problemas globales planteados en el trabajo.

En síntesis, el análisis de este breve lapso a través de una fuente, a la vez parca e incompleta, sugiere que a partir de 1836 comenzó a gestarse una nueva y más estrecha relación comercial entre el Interior y la capital de la confederación. El inicio del bloqueo francés y las repetidas modificaciones que paulatinamente iban anulando el efecto proteccionista de la Ley de $1835,{ }^{63}$ pondrán pronto fin a esta atípica situación, para retornarla a aquellos tiempos en donde la desintegración económica del espacio era algo más que un peligro latente.

\section{LAPSO 1839-1850}

A pesar de ser el más largo, este es el periodo para el cual la documentación es casi completa; sólo falta la referente al primer cuatrimestre de 1839. Además aumenta la calidad de la fuente, pues gran parte de los Manifiestos consignan los precios de aforo de las mercancías.

Habíamos dicho que las diferentes formas de concebir la vinculación con

63 Sobre este tema, véase Burgin, Aspectos, 1987, pp. 308-314. la Europa industrializada (librecambio o proteccionismo) rápidamente devino en una necesidad mucho más perentoria: la de organizar institucionalmente al país, lo que a su turno generó nuevas controversias, las cuales tuvieron su crudo reflejo en las luchas civiles. Y si bien para este periodo lo peor en esta materia casi ha quedado atrás, Corrientes, posiblemente la más reluctante a la política implementada desde Buenos Aires, continúa envuelta en serios enfrentamientos con esta última -los cuales repercutieron negativamente en su economía, al punto de que sus lazos comerciales con el puerto en ocasiones fueron muy débiles y en otras inexistentes-, eventualmente aliada con el Paraguay, que comienza a salir de su aislacionismo -en el que estuvo inmerso a partir de 1810- luego del fallecimiento de Gaspar Rodríguez de Francia (1840), mientras que Entre Ríos lleva el mayor peso de la carga que significó el "sitio grande" de Montevideo. ${ }^{64}$ Por su parte el principal puerto de la confederación rosista sufrirá dos grandes bloqueos en un corto lapso, y si bien Buenos Aires salió políticamente fortificada de ambos conflictos con las potencias europeas, es indudable el perjuicio económico que los mismos ocasionaron.

En fin, en este periodo veremos que las conclusiones provisionales que habíamos extraído del análisis del periodo $1831-1835$ se van confirmando, al menos en términos generales, teniendo en cuenta que los flujos mer-

64 Halperin Donghi, Revolución, 1980, p. 294. 
cantiles han crecido considerablemente, aunque más lo hayan hecho los valores comerciados en virtud de la inflación registrada en el lapso. De las cifras obtenidas, se desprende que el peligro de desintegración económica del espacio que pareció existir hacia 1835, continuaba vigente en 1850 (si bien desde el punto de vista político, el poder rosista estaba más sólido, dado el prestigio alcanzado en materia de política exterior).

\section{Los flujos comerciales}

El lapso en estudio comienza en pleno bloqueo francés del puerto de Buenos Aires. Obviamente, en esa situación el flujo de las mercancías del Interior que tenía como destino final -previo paso por la aduana porteña- el mercado ultramarino, disminuía sensiblemente mientras que el destinado al consumo interno de la capital (originario, por lo general, de las subregiones que menos lazos tenían con aquélla en tiempos normales) crecía. De todos modos, este incremento derivado de un proteccionismo forzado no alcanzaba a compensar lo perdido en aras del librecambio ejercitado desde el poder portuario.

Ejemplos de lo expresado se pueden encontrar en el análisis de 1840. De los casi 337000000 de pesos que sumó el monto comerciado total del periodo, al año 1840 le corresponden poco más de 4500000 (véase Apén. dice, cuadro 14); del total de cueros vacunos llegados a la aduana de Buenos Aires en el lapso estudiado -más de 5000000 - sólo 14658 lo hicieron en 1840 , y de ellos, entre los que no se encontraba ninguno que fuera sala. do, más de 10000 procedian de Córdoba y Santiago del Estero. En fin, en el año en cuestión, el Litoral, como región, y los cueros vacunos, como producto exportable, pierden la preponderancia que les habíamos notado en el periodo 1831-1835, precisamente por estar cerradas las salidas a ultramar.

Como contrapartida, el Interior cobra cierta fuerza pues sus frutos son apetecidos en la capital, que no puede ser abastecida desde el exterior. (EI caso de los caldos cuyanos es bastante sugerente: buena parte de las remesas de la región hacia el puerto se efectúan en épocas de bloqueo). Este despertar del Interior durará poco: una vez abiertas las vías de comunicación hacia el viejo continente, Norteamérica, Brasil y Cuba, el "Litoral de los Ríos" y su producto más preciado, los cueros vacunos, superarán con largueza la performance de 1831-1835.

En síntesis, 1840 es un año atípico y de alli que las subregiones que más aportan en la conformación del monto comerciado sean San Juan (27\%) y Tucumán (23.26\%). De operar normalmente el puerto de Buenos Aires, la situación antedicha es totalmente impensable para los tiempos que estamos tratando; en 1841 el monto comerciado pasó los 33 millones, y San Juan y Tucumán apenas alcanzaron $1.29 \%$ y $0.49 \%$, respectivamente, de dicho monto -los que traducidos a pesos papel significaron bastante menos de la mitad de lo que obtuvieron un año antes-, mientras que los cueros vacunos superaron las 560000 
unidades (y más de $\mathbf{4 7 0} 000$ las aportó el Litoral).

Se puede observar, a través del cuadro 9, lo poco que ha cambiado el panorama que habíamos presenciado en la década de 1830. En cuanto a las regiones, el Litoral sigue teniendo la mayor participación en la composición total del monto comerciado, mientras que la región central y, sobre todo Cuyo, se encuentran, en ese aspecto, muy rezagadas.

Participación del "litoral de los ríos" en el total del monto comerciado, 1839-1850

Río Paraná

$\begin{array}{cc}\begin{array}{c}\text { Costa occidental } \\ \text { (Bs.As.-S.Fe) }\end{array} & \begin{array}{c}\text { Costa oriental } \\ \text { (Ctes.-Parana) }\end{array} \\ & \\ 2.71 \% & 7.94 \% \\ 10.09 \% & 12.96 \% \\ 12.80 \% & 20.90 \%\end{array}$

$33.70 \%$

Río Uruguay

$\begin{array}{cc}\text { Costa occidental } & \text { Costa oriental } \\ \text { (Entre Ríos) } & \text { (Uruguay) }\end{array}$

$18.42 \%$

$25.15 \%$

$43.57 \%$

De las subregiones, Entre Ríos no sólo continúa siendo la más importante, sino que incluso ha tenido un crecimiento significativo (pasa de $24.20 \%$ a $31.38 \%$ ), si bien el aumento porcentual que registró la antigua Banda Oriental es mucho más llamativo (de $15.55 \%$ subió a $25.15 \%$ ); tam- bién Santa Fe consigna una leve alza. En la situación opuesta se hallan Buenos Aires, Corrientes y Córdoba, que pierden, en conjunto, lo que han ganado las anteriores (para quedar en $2.71 \%, 7.94 \%$ y $10.13 \%$, respectivamente). El resto de las subregiones mantiene el nivel de participación en la conformación del monto total, aunque con leves variaciones.

Y aquí sí se notan algunos cambios sustanciales, si comparamos estos porcentajes con los obtenidos en el lapso 1831-1835. El más significativo es el que nos indica que ahora las subregiones más dinámicas ya no se encuentran sobre el Paraná, sino que son las bañadas por su hermano menor las alcanzadas por un proceso que había comenzado a vislumbrarse en la década de 1830.65

El limitado ascenso de Santa Fe, la cual parece estar dejando atrás el fantasma del estancamiento que le habíamos observado en la primera mitad de la década de $1830^{66}$ y el consignado

65 Ibid., p. 294.

66 Hacia finales de 1847, William MacCann, en su viaje desde Buenos Aires a Rosario, scñalaba al acercarse a la última de las mencionadas: "Atravesamos campos de buenos pastos, pero escasos de ganado". Véase MacCann, Viaje, 1985, p. 223. Sobre la misma zona, Sarmiento, en su marcha con el Ejército Grande, expresaba, no sin cierta dosis de exageración, en enero de 1852: "Esta tierra privilegiada, dotada por la naturaleza de productos iguales a los que el trabajo dcl hombre obtendría sólo por una labor incesante, está despoblada y lo ha estado siempre. No hay una sola casa, no hay en esta vasta extension una sola cabeza de ganado. Los gamos son los poseedores de esta parte del territorio argentino" . Véase Sarmicnto, Campa. ña 1962, p. 62 (cursivas nuestras). 
Cuadro 9. Flujo comercial hacia Buenos Aires: total de valores comerciados, $1839-1850^{\mathrm{a}}$

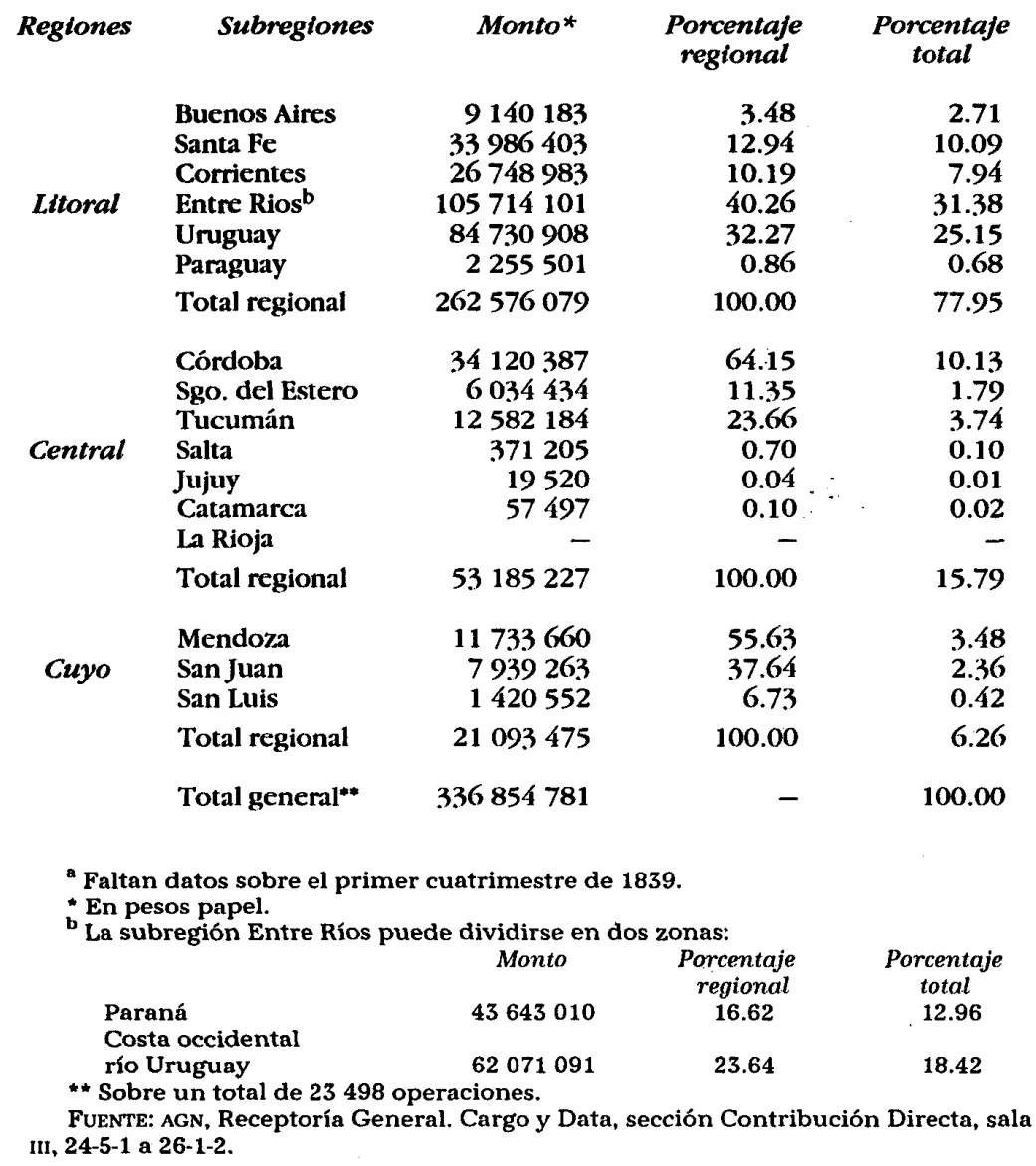




\section{SECUENCIA}

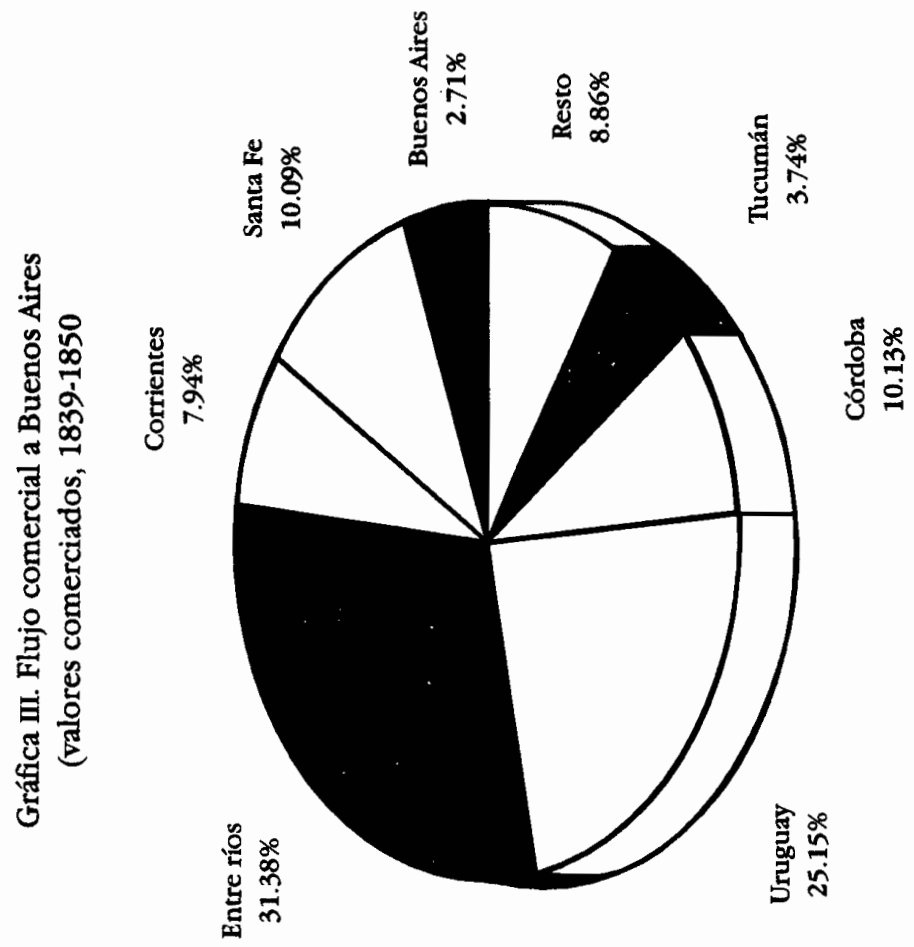




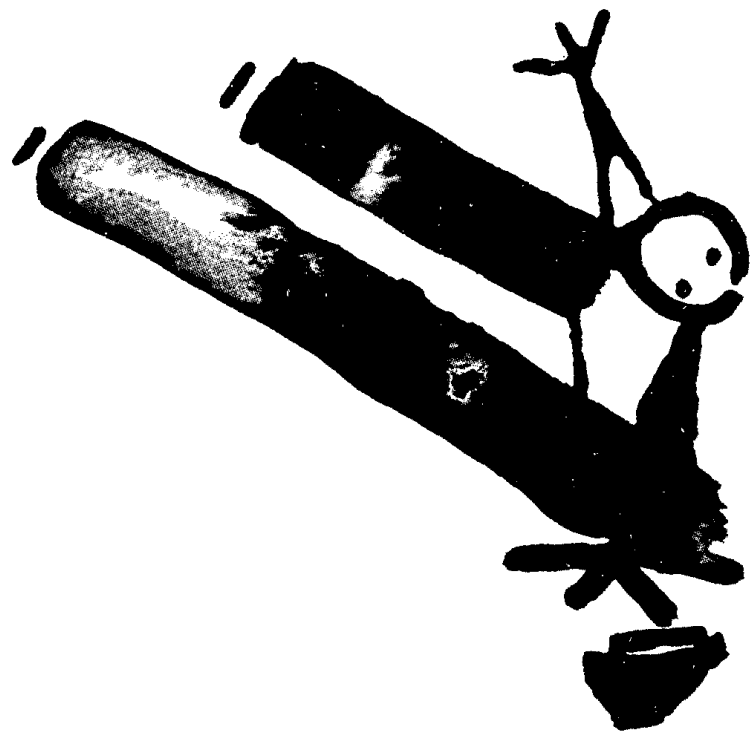

para Paraná, no alcanzan para compensar las bajas producidas en Buenos Aires, cada vez más compenetrado en su simple misión de intermediario entre el Interior y la aduana porteña, y Corrientes, repetidamente embarcada en sangrientas luchas contra el poder rosista. 67

El panorama sobre el río Uruguay es totalmente distinto: el crecimiento en la participación del total del monto comerciado observado, tanto en una como en otra orilla, permite concluir que el eje del tráfico comercial rioplantense se ha trasladado hacia esta vía fluvial.

67 El aporte paraguayo es demasiado limitado como para tomarlo en cuenta.
Es probable que parte de la explicación de este crecimiento, observado especialmente en la zona que hemos denominado costa occidental del río Uruguay, dentro de la subregión/provincia Entre Ríos, resida en el acuerdo político tejido entre Rosas y los entrerrianos orientales, entre los que iba creciendo la figura de Urquiza. A través de dicho acuerdo, concertado en los inicios del decenio anterior, Buenos Aires debió aceptar una mayor autonomía política de la provincia, además de conceder ciertas ventajas económicas, como la autorización para la instalación de saladeros; por su parte, los entrerrianos orientales ofrendaron su distanciamiento de la oposición rosista exiliada en Montevideo con la que, eventualmente, se 
había aliado para enfrentar a las autoridades provinciales. 68

De todos modos, debemos dejar en claro que el crecimiento de Entre Ríos no le permite, ni con mucho, acercarse al que ha experimentado la provincia de Buenos Aires a partir de la tercera década del siglo. En efecto, en cuanto a la expansión del Litoral a partir de 1830 y el peso que Buenos Aires tiene en el total de las exportaciones, sería oportuno situar ambos hechos en su real dimensión. Lo cierto es que aquélla

está todavía lejos de significar una rivalidad seria para Buenos Aires [...]; en los años de mayores exportaciones, las de tasajo de Entre Ríos son del orden del $10 \%$ de las que puede ofrecer la fatigada y poco rendidora industria saladeril porteña. ${ }^{69}$

Por último, en el Apéndice, a través de la gráfica $v$ se podrán apreciar los flujos mercantiles generales año por año, y en la gráfica $V I$ los regionales en porcentajes, comparando los periodos $1831-35$ y $1839-50$.

\section{Componentes del flujo}

Cueros: si bien nuestra intención es ilustrar sobre la cantidad de cueros enviados desde las provincias a Buenos Aires - lo cual podemos observar a través del cuadro 10 y su apéndicehabíamos dicho que sería interesante,

68 Sobre este tema, consultar a Chiaramonte, "Legalidad", 1986, pp. 182 y 193-195. 296.

69 Halperin Donghi, Revoluctón, 1980, p.

EL INTERIOR FRENTE A BUENOS AIRES para completar el panorama, tratar de acercarnos a la cifra total de los llegados a la aduana porteña, pues la diferencia estaría indicando, grosso modo, el aporte de la región casi no tratada en este trabajo, es decir la campaña bonaerense, especialmente la del sur. En principio, sería conveniente insistir en que nuestros datos sobre la campaña norte son limitados; los productos que han llegado al mercado porteño son los muy cercanos al río, faltando los de tierra adentro que de seguro se transportaban en carretas (obviamente tampoco se encuentran registrados los de las campañas oeste y sur).

Las cifras del comercio exterior (extraídas de la obra de Parish) nos han permitido, creemos, hacer una estimación bastante cercana a la realidad, al deducirles las obtenidas en nuestra investigación.

Las cifras sobre cueros vacunos corrobarían grosso modo las afirmaciones de Parish, según el cual

la sola provincia de Buenos Aires [...] contribuye hoy [se refiere al bienio 1850-1851] como con dos terceras partes de todo el número de cueros que se expenden en aquel mercado, siendo lo restante especialmente introducido a Buenos Aires de las provincias ribereñas $\{\ldots\}$ Comparativamente, son muy pocos los que se traen de las provincias del Norte. ${ }^{70}$

En cuanto a los cueros caballares, la situación es totalmente distinta: son las provincias, especialmente las litoraleñas (junto con la subregión Uru-

70 Parish, Buenos Aires, 1958, pp. 552-553. 
Exportación de cueros: Buenos Aires frente al Interior*

\begin{tabular}{|c|c|c|c|c|c|}
\hline \multicolumn{6}{|c|}{ Cueros vacunos } \\
\hline \multirow[b]{2}{*}{$\begin{array}{l}1849 \\
1850\end{array}$} & Exportación & $\begin{array}{c}\text { Produccton } \\
\text { interior }\end{array}$ & Porcentaje & $\begin{array}{l}\text { Produccton } \\
\text { Buenos Aires }\end{array}$ & Porcentaje \\
\hline & $\begin{array}{l}2961342 \\
2424251\end{array}$ & $\begin{array}{l}772296 \\
869287\end{array}$ & $\begin{array}{l}26.08 \\
35.86\end{array}$ & $\begin{array}{l}2189046 \\
1554964\end{array}$ & $\begin{array}{l}73.92 \\
64.14\end{array}$ \\
\hline \multicolumn{6}{|c|}{ Cueros baguales } \\
\hline & Exportacton & $\begin{array}{c}\text { Produccton } \\
\text { intertor }\end{array}$ & Porcentaje & $\begin{array}{l}\text { Produccion } \\
\text { Buenos Aires }\end{array}$ & Porcentaje \\
\hline $\begin{array}{l}1849 \\
1850\end{array}$ & $\begin{array}{l}238514 \\
187 \quad 107\end{array}$ & $\begin{array}{l}170758 \\
113404\end{array}$ & $\begin{array}{l}71.59 \\
60.61\end{array}$ & $\begin{array}{l}67756 \\
73703\end{array}$ & $\begin{array}{l}28.41 \\
39.39\end{array}$ \\
\hline
\end{tabular}

- Las cifras de exportación son de Parish, Buenos Aires, 1958, p. 512; las de la producción del Interior incluyen cueros secos y salados, no así curtidos, cuya cantidad es francamente despreciable. Debemos aclarar que si bien la subregión Buenos Aires envia una fracción (no demasiado numerosa, por cierto) de aquéllos, buena parte de la misma provenía de otras áreas.

guay), las que más aportan al flujo exportador. El significativo envío de este tipo de cueros, especialmente los de yegua, reflejaría, por un lado, la abundancia de recursos naturales como consecuencia de la multiplicación natural del ganado (acaecida durante el segundo bloqueo, al cesar la matanza ante la imposibilidad de exportar los derivados a los mercados ultramarinos) $y$, por otro, la época de paz que gozó el país hacia fines del lapso rosista, pues debemos recordar la importancia militar que tenía el equino en aquellos tiempos.

Retomando el tema de las exportaciones desde el Interior a Buenos Aires, habíamos visto que en la primera mitad de la década de 1830, los cueros, especialmente los vacunos, ocupaban una significativa porción -alrededor de 60\%- del monto comerciado total, si bien a fines del mismo decenio habíamos notado cierta declinación en los porcentajes.

Entre 1841 y 1845 se produjo una considerable entrada de cueros vacunos además de una duplicación de los precios con respecto a 1831-1835, con lo cual la parte que les correspondió en el monto comerciado alcanzó niveles similares $e$ incluso superiores al obtenido en aquel lapso. Sin embargo, durante la segunda mitad de la década de 1840 , además de mermar las entradas, los precios registraron una sensible caida, lo que en definitiva dio como resultado que el porcentaje dentro del monto comerciado se redujera. De todos modos, debemos dejar bien claro que, en algunos casos, sólo hemos manejado cifras estimati- 
象

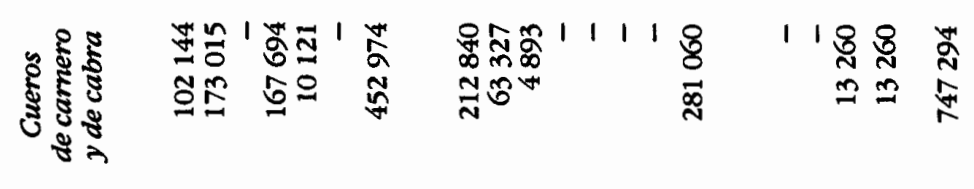

$\underset{\substack{\infty \\ \infty}}{\infty}$

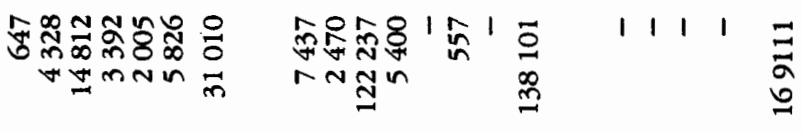

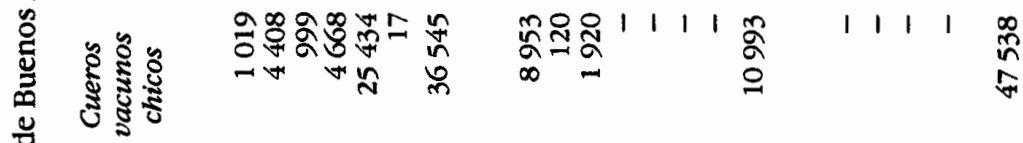

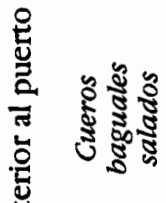

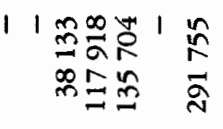

1111111

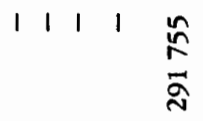

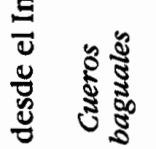

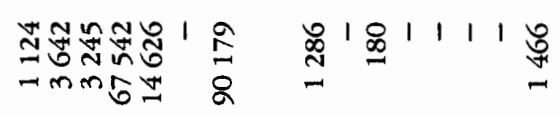

$\begin{array}{lllll}1 & 1 & 1 & 1 & \frac{n}{\delta} \\ & & & \frac{n}{a}\end{array}$

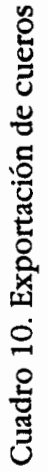

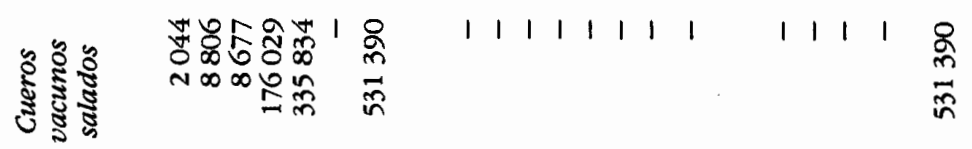

:웡

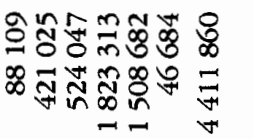

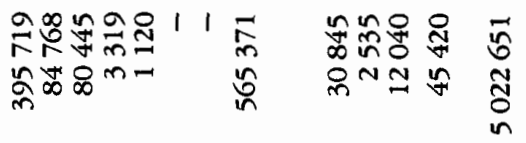

$\frac{5}{5}$

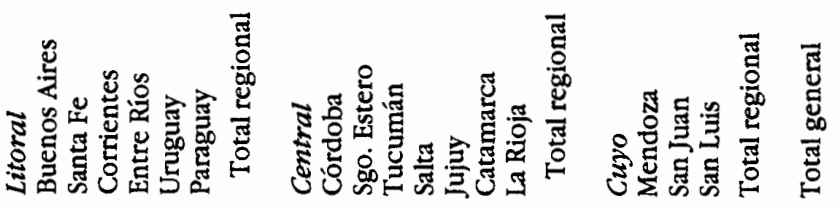




\section{SECUENCIA}
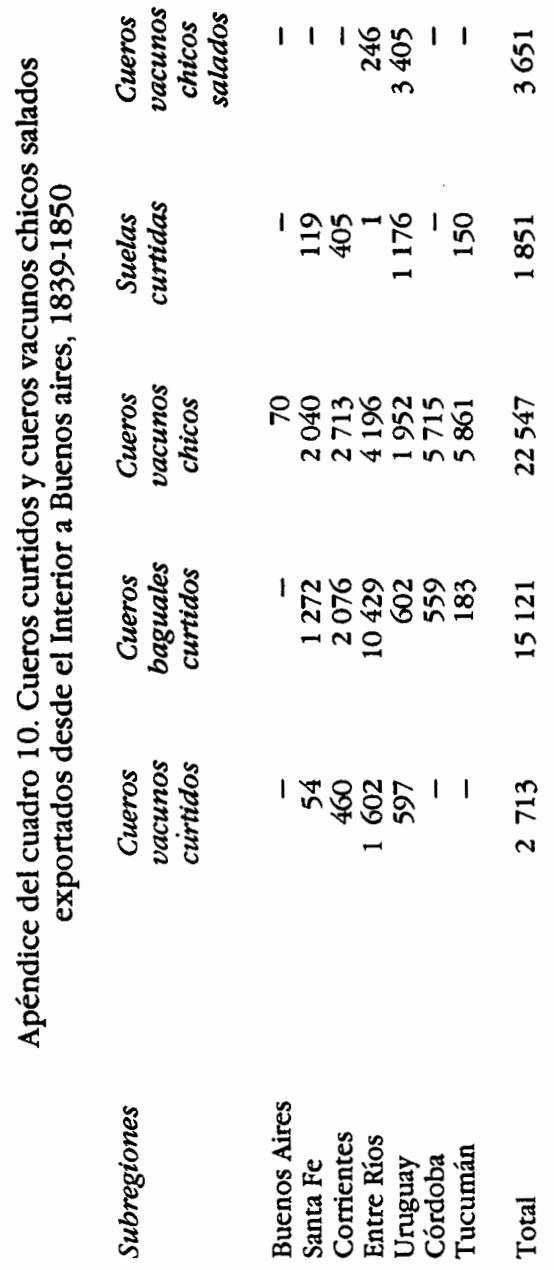


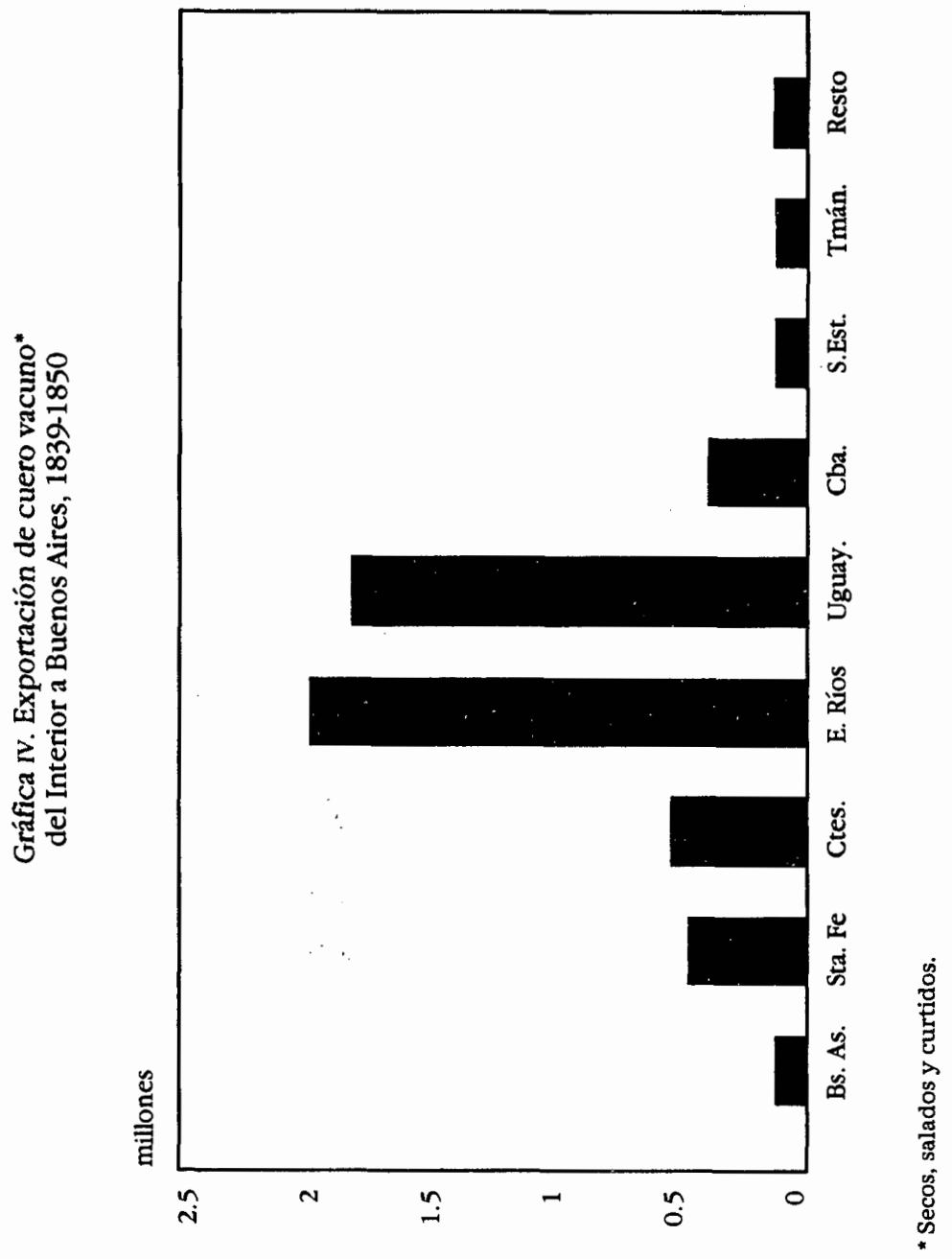


vas de un lapso donde se produjeron considerables oscilaciones en las entradas (véase gráfica VII en el Apéndice) y en los precios de los cueros como consecuencia de los bloqueos que sufrió el puerto de Buenos Aires. Aún así, y más allá de estas consideraciones, parecería que la porción que les corresponde a los cueros dentro del monto comerciado hacia fines del periodo rosista sufrió una mengua sig. nificativa.

Si bien Halperin Donghi ha señalado que es poca la influencia de los precios mundiales pecuarios en el aumento o descenso de la producción rioplantense (sobre la cual tendría más incidencia el clima o la situación política), ${ }^{71}$ nos preguntamos si pudo existir cierta consonancia entre la tendencia a la baja de aquéllos ${ }^{72}$ y el descenso observado en los de la plaza de Buenos Aires, y si esto alcanza para explicar la reducción porcentual de los cueros en el total del monto comerciado, o si, además, al repercutir negativamente en las economías provinciales, en especial en las del Litoral, donde se emipezaba a vislumbrar cierto agotamiento del sistema, éstas comenzaron un proceso de diversificación de la producción como un saludable intento de supervivencia económica, agudizando aún más la merma porcentual de los cueros.

Si en la provincia de Buenos Aires el triunfo de los cueros vacunos salados sobre los secos data de la tercera

71 Halperin Donghi, "Expansión", p. 62.

72 Ibid., p. 60-63. Chiaramonte, Mercaderes, p. 216. En el primer caso se trata de los precios en el mercado de Londres; en el segundo, de los de Hamburgo. década del siglo $X I X,{ }^{73}$ la situación en el Litoral a fines de la quinta década indica, en cambio, que los primeros apenas llegan a $9.63 \%$ (considerando a ambas categorías como un todo). Muy distinto es el caso de los cueros baguales: los salados ocupan $76.19 \%$ del total. Los principales centros de producción de los cueros salados tanto bovinos como caballares- son Uruguay y Entre Ríos, en ese orden; y si bien menores, no son desdeñables los envíos correntinos. Los cueros rioplatenses eran preferidos en los mercados europeos por su resistencia y grosor. Una vez muerto el animal, se lo desollaba (parte de la calidad del cuero dependía del hecho de no tener adherencias de carne), luego se procedia al estanqueo y se continuaba con la salazón (baño de salmuera); por último se apilaban los cueros, dejándolos estacionados de una a dos semanas. El cuero seco era bastante más liviano que el salado, pero en relación obtenía una mejor cotización en los mercados internacionales. ${ }^{74}$

Tejidos "de la tierra": nos referimos, vale la pena repetirlo, a los ponchos "llanos", frazadas y jergas de lana, de confección sencilla y bajo costo, llegados desde Córdoba, y a los ponchos "mestizos" de Santiago del Estero, más elaborados, de lana y algodón (aunque también los había de lana solamente) y que alcanzaban mayor precio en el mercado porteño, donde la presencia de estos textiles, a fines de la primera mitad del siglo XIX, era 286.

73 Halperin Donghi, Revolucion, 1980, p. ${ }^{74}$ Macchi, Urquiza, 1971, pp. 77-80. 
mucho más significativa de lo que se podría suponer. 75

Los tejidos "de la tierra" parecen resistirse plenamente a una supuesta declinación que se habría producido a partir de la segunda década del siglo. En efecto, la media anual de piezas textiles llegadas a Buenos Aires durante el lapso en estudio alcanza, según los datos consignados en el cuadro 11 , a las 45092 , lo que significa un considerable incremento si lo comparamos con las casi 38000 que llegaban por año a la aduana porteña entre 1831-1835. Más aún, si observamos los seis últimos años del periodo, en los del segundo bloqueo (1845-1847) entran alrededor de 25000 piezas anuales, para superar con holgura las 60000 entre 1848 y 1850 . Estas cifras no se compadecerían, por un lado, con el tan meneado argumento de la competencia europea, y por otro, con una presunta desaparición lenta y gradual de los tejidos "de la tierra" pues en el menor de los casos los textiles de la región central parecen gozar todavía de buena salud. ${ }^{76}$

Obviamente que nos referimos a una cuestión meramente numérica y

\footnotetext{
75 También hemos constado envíos de otras áreas, por ejemplo San Luis y Tucumán, además de los reexportados a través del Paraná.

76 De todos modos, Halperin Donghi ya señaló que "la [producción] de telas de lana iba a mantener una vitalidad comprobada aun en la séptima década del siglo" pero que dicha situación no bastaba "para afectar el cuadro general: una industria artesanal ya escasamente vigorosa sobrevive a partir de $1810 \mathrm{en}$ un lento descenso que llenará aún tres cuartos de siglo; es precisamente el ferrocarril quien pone fìn a su agonia". Véase Halperin Donghi, Revolución, 1972 , p. 108.
}

no a valores: si a fines del siglo XVIII un poncho "llano" cordobés y un cuero vacuno seco tenían un precio similar, cinco décadas más tarde se necesitaban varias unidades del primero para cubrir el valor del segundo. En fin, debemos recalcar "la limitada relevancia, en el marco de los intercambios internos, que poseían estos textiles de la tierra en el mercado de Buenos Aires". 77

Cabría recalcar, por último, las causas de la tenaz resistencia que opusieron estos textiles ante el embate desatado, luego de 1810 , por parte de las telas importadas. Las mismas serian de carácter económico (los bajos costos de producción de estas piezas, al ser elaboradas en el seno familiar y en el marco de una economía campesina) y hasta sociológico (la preferencia de tejidos de baja calidad, pero de llamativos colores, lo que explicaría la gran aceptación que tenían los vistosos ponchos santiagueños en el mercado porteño).

Caldos "de la tierra": la situación de los caldos cuyanos es totalmente distinta a la de los textiles. El aguardiente y el vino de San Juan y Mendoza tienen una presencia cada vez más simbólica en el mercado porteño: apenas 1522.92 y 260.17 arrobas anuales, respectivamente.

Estos promedios no sólo están ya muy lejos de los alcanzados hacia fines de la década de 1810 y principios de la de 1820 , cuando ya se empezaba a notar la declinación de la vitivinicul-

77 Garavaglia y Wentzcl, "Nuevo", 1900, pp. 232-234. 


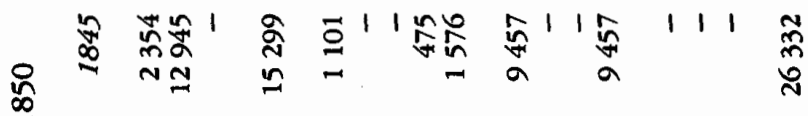

$\frac{1}{2}$

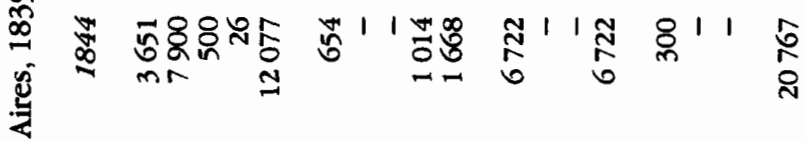

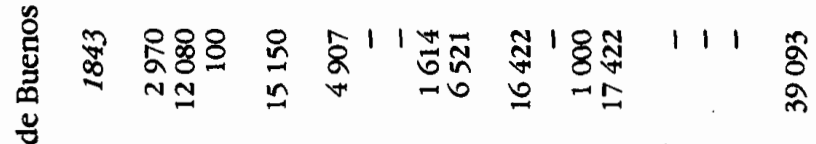

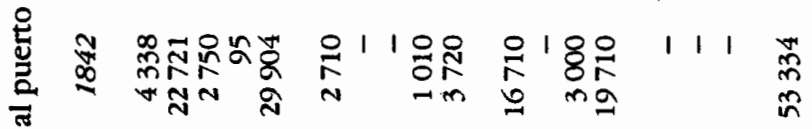

总

若

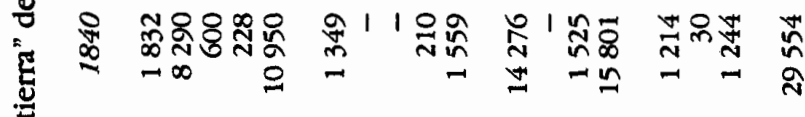

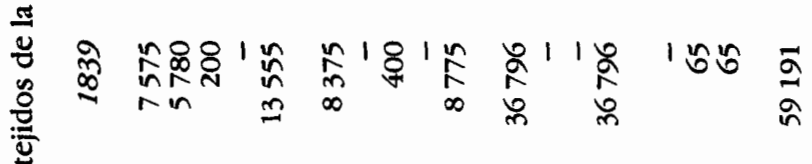

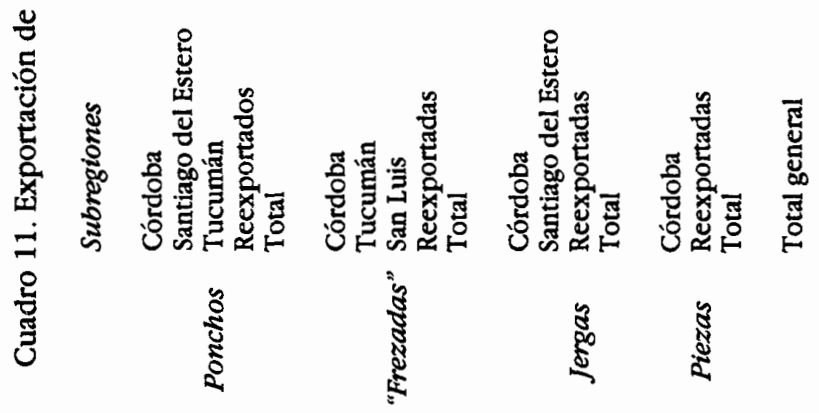




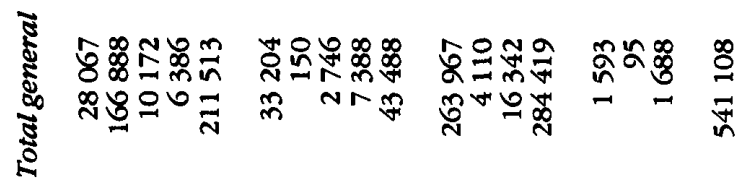

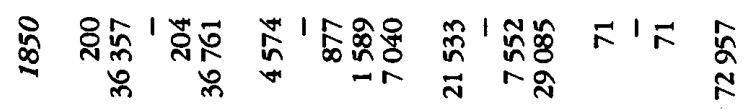

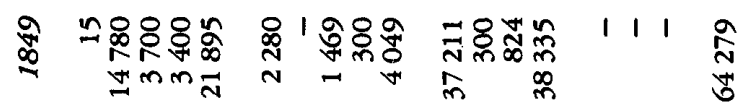

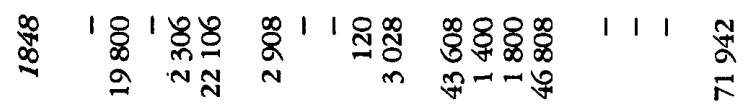

苦

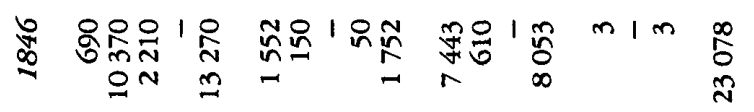

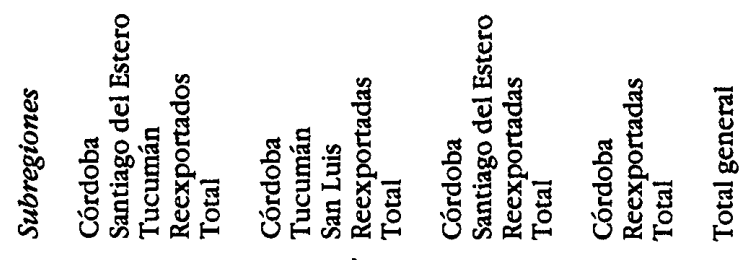

¿

है

है है. 
tura cuyana, sino que se han reducido con respecto a los obtenidos para el lapso 1831-35. Tanto las luchas civiles como la introducción masiva de caldos europeos han tenido que ver en esta virtual desaparición de la producción vitivinícola de Cuyo.

Las cifras de la exportación de caldos consignada, reflejan con crudeza la debilidad de los lazos comerciales entre la región y el puerto. Por lo que, a pesar de las dificultades que Mendoza y San Juan tenían en entablar relaciones normales con Chile, restricciones que no sólo provenían desde Buenos Aires, sino que en ocasiones, como ocurrió entre 1842 y 1846 , se originaban en Santiago, las provincias cuyanas, ante la falta de una alternativa viable, se recostaron hacia el Pacífico, más aún cuando sus productos, en especial las frutas secas y el jabón, tuvieron una significativa receptividad en el mercado californiano, ${ }^{78}$ donde se había desatado la fiebre del oro. A su vez Chile, embarcado en nuevos ciclos mineros (el de la plata, en Chañarcillo, desde la década de 1830 , y el del cobre, un decenio más tarde) necesitaba importar, entre otras cosas, ganado en pie, y Cuyo comenzó la reconversión de su economía, reemplazando las vides y el cereal por campos de alfalfa para la cría de vacadas y recuas locales, y el engorde de las provenientes de la región central. ${ }^{79} \mathrm{La}$ vitivinicultura cuyana, en el marco de

${ }^{78}$ Segreti, Economia, 1981, pp. 203-205.

79 Halperin Donghi, Revolucion, 1980, pp. 289-290. En Catamarca y La Rioja se daba una situación similar. las relaciones de producción coloniales, era definitivamente una cosa del pasado.

Otros: a través del cuadro 17 , situado en el Apéndice, se puede observar la importancia que tuvieron distintas producciones en las diversas subregiones del espacio en estudio. Se destacan la lana cordobesa, cuyo precio por arroba llegó hacia mediados de siglo hasta los 45 pesos, bastante más alto que el que tenía la lana litoraleña; aún no hemos podido encontrar una explicación satisfactoria de este fenómeno. Fue muy importante también el ciclo de la harina cuyana, la cual registró considerables oscilaciones en el precio. En fin, los pellones tucumanos, los cordobanes, los cereales santafesinos y el tasajo oriental tienen una presencia considerable en el mercado porteño hacia fines del periodo rosista; tanto este último como aquélla, se van valorizando a lo largo del periodo hasta alcanzar e incluso superar el precio de los cueros vacunos.

\section{CONCLUSIONES}

La desarticulación del mercado rioplatense-altoperuano a partir de $\mathbf{1 8 1 0}$ producirá en el primero de los espacios mencionados el comienzo de un proceso sin retorno que culminará en una vinculación plena con el Atlántico. Obviamente, la historia terminó así pero creemos que no necesariamente tuvo que ser de ese modo; en todo caso, hay varias razones para pensar que durante la primera mitad del siglo XIX pudo haber más mutilaciones que las sufridas a partir de la 
Cuadro 12. Exportación de "caldos de la tierra" cuyanos al puerto de Buenos Aires, 1839-1850*

\begin{tabular}{|c|c|c|c|c|c|c|c|c|}
\hline \multirow[b]{2}{*}{ Años } & \multicolumn{3}{|c|}{ Aguardiente } & \multicolumn{5}{|c|}{ Vino } \\
\hline & Mendoza & San Juan & $\boldsymbol{R}$ & Total & Mendoza & SanJuan & $\boldsymbol{R}$ & Total \\
\hline 1839 & 626 & 5092 & - & 5718 & 1588 & 68 & - & 1656 \\
\hline 1840 & 388 & 4584 & 24 & 4996 & 756 & 88 & - & 844 \\
\hline 1841 & 4 & 1230 & 48 & 1282 & 28 & 16 & - & 44 \\
\hline 1842 & 24 & 311 & - & 335 & 16 & - & - & 16 \\
\hline 1843 & 8 & 226 & 64 & 298 & 108 & 8 & 6 & 122 \\
\hline 1844 & 186 & 628 & - & 814 & 28 & 12 & - & 40 \\
\hline 1845 & 12 & 190 & 4 & 206 & - & - & 12 & 12 \\
\hline 1846 & 12 & 586 & - & 598 & 100 & 56 & - & 156 \\
\hline 1847 & 68 & 1438 & 12 & 1518 & 44 & 38 & 4 & 86 \\
\hline 1848 & 78 & 2218 & 86 & 2382 & 60 & - & 4 & 64 \\
\hline 1849 & - & 32 & - & 32 & - & 4 & 6 & 10 \\
\hline 1850 & 88 & 8 & - & 96 & - & 72 & - & 72 \\
\hline Total & 1494 & 16543 & 238 & 18275 & 2728 & 362 & 32 & 3122 \\
\hline
\end{tabular}

revolución en el espacio presuntamente dominado por Buenos Aires. ${ }^{80}$

No todas las regiones-provincias, ya fuera por la calidad y cantidad de sus recursos naturales, y/o por razones geográficas, pudieron adaptarse rápidamente a la dislocación del antiguo orden y asimilar las reglas de juego que el nuevo proponía. De alli que la conexión comercial de aquéllas con Buenos Aires tuvo distintos niveles de intensidad, pasando desde el tendido de unas débiles ligaduras, casi inexistentes, hasta el entrelazamiento de fir-

80 En realiclad, las regiones interiores terminarán por integrarse al espacio económico tioplatense a medida que el capitalismo madurase en estas tierras y un signo vital de tal maduración sería la extensión de la red ferroviaria. mes nexos con el puerto, siempre en función de un ávido mercado exterior de ciertas materias primas, en especial las derivadas de la ganadería.

Si en el último de los casos mencionados se encontraban las provincias litoraleñas, Córdoba y en menor medida Tucumán, no por su mejor posición respecto a las que se hallaban en el primero se conformaban con la parte que les tocaba en suerte. Sabian que más allá de los distintos intereses en torno al proteccionismo o al librecambio, la discusión de fondo pasaba por la organización constitucional que cercenaría el poder político-económico de Buenos Aires para compartirlo entre todos los integrantes de la nueva nación. 
Por supuesto, la situación en el resto del Interior es mucho más preocupante; extensas zonas del espacio rioplantense parecen obligadas a orientar sus producciones hacia otros mercados. Así, mientras Cuyo mira hacia el Pacífico, el noroeste aparentemente se recuesta sobre Bolivia y Perú, pues poco tienen que ofrecer en el mercado porteño y/o se encuentran demasiado alejadas del mismo como para hacer beneficioso su acercamiento al puerto. De todos modos, no poseemos datos concretos sobre dichas conexiones y sólo podemos aventurar que las mismas permitieron un cierto desahogo a esas economías postergadas luego del reacomodamiento producido a partir de 1810 , alivio que sin embargo pareció, por momentos, comprometer la integración del espacio económico dominado por la antigua capital virreinal. (Por supuesto que estos conflictos económicos se veían reflejados en los políticos, cuya más trágica manifestación fueron las luchas civiles).

Por el contrario, hemos obtenido cifras que nos ilustran sobre la articulación de todo el espacio rioplantense con Buenos Aires durante la extensa etapa rosista. El estudio de los flujos comerciales hacia el puerto durante la década de 1840 confirma, en términos generales, las conclusiones provisionales a las que habíamos arribado luego del tratamiento del tema en cuestión para el periodo 1831-35. De las tres regiones en que se dividió el espacio, el Litoral es, largamente, la que más firmes lazos mantiene, a través de Buenos Aires, con los mercados ultramarinos.
Dentro de la región, Entre Ríos se consolida como la provincia más pujante, con un relativo equilibrio en el desenvolvimiento económico de las dos grandes zonas que la componen: la bañada por el Paraná, al oeste, y la que se recuesta sobre el otro gran río. El dinamismo observado en esta última, sumado al que se desarrolla en la orilla de enfrente, territorio de la antigua Banda Oriental, permite concluir que el eje del tráfico comercial rioplantense se ha trasladado desde el Paraná al Uruguay. De las restantes sur bregiones, sólo Santa Fe muestra alguna recuperación respecto al lapso estudiado anteriormente; Buenos Aires, esa pequeña zona de la campaña del norte cercana al río Paraná, cada vez más se limita al papel de intermediario entre los productores del Interior y el puerto exportador, y Corrientes continúa demasiado embarcada en sus sangrientas luchas con el poder rosista, como para poder prestar atención a su progreso económico. Asunción, por su parte, recién comienza a despertar de su largo letargo.

De la región central no hay demasiado para destacar salvo que ha habido un retroceso en sus porcentajes de participación en la composición total del monto comerciado respecto a 1831-35, y la más perjudicada de todas las subregiones/provincias fue Córdoba, con una baja de seis puntos; de cualquier modo, continúa siendo la más firmemente vinculada al Atlántico. Las demás tratan de involucrarse en los distintos circuitos mercantiles surgidos del reacomodo del sistema económico luego del final de las guerras de Independencia, pero sobre este tema no tenemos cifras precisas. 


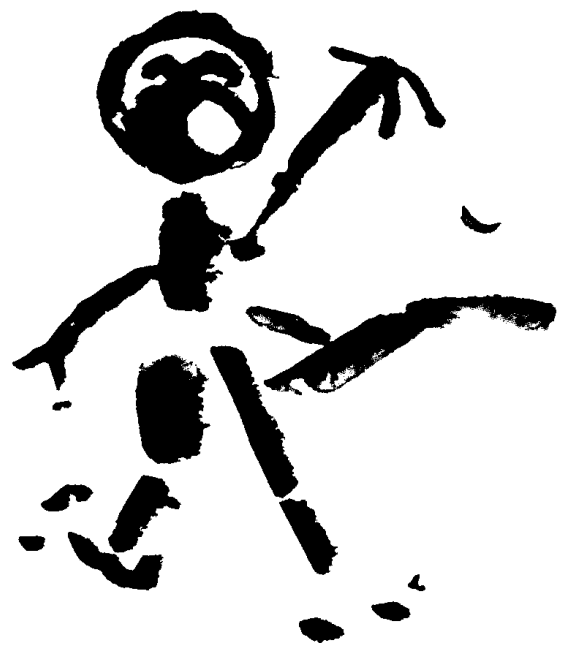

Algo similar sucede con Cuyo, que, salvo en los periodos de bloqueo, no tiene lazos demasiado estrechos con Buenos Aires; en todo caso, mantiene -aunque con una leve mejoría- los niveles de participación en la totalidad del monto. Chile se convierte así en la mejor $-y$ a veces única- alternativa para la salida de los excedentes de su producción y la importación de lo imprescindible, aunque tampoco en este caso poseemos datos puntuales.

Los productos pecuarios son los principales componentes del flujo comercial, y entre ellos se destacan los cueros vacunos. En términos de valor, sin embargo, la porción que les corresponde dentro del monto total ha disminuido en relación a los inicios de la época rosista. La baja de los precios internos (quizás en concordancia con la de los internacionales) fue la causa directa de esta merma; pero es posible que las provincias, ante esta situación, multiplicaran esfuerzos para diversificar su producción, cuyos excedentes significaron un aumento de la parte no correspondiente a los cueros en el monto comerciado total. ${ }^{81} \mathrm{Hemos}$ ob-

${ }^{81}$ Según las estimaciones gencrales que hemos realizado, el monto comerciado estaría integrado en 55\% por los cueros (a los aquí considerados habría que sumarles otros, por ejemplo los de "león", "tigre", vicuña, oso, etc.), 15\% por los que hemos denomiando "flujos secundarios", $2.5 \%$ por los tejiclos "de la tierra" y otro tanto por los caldos del mismo origen, correspondiendo el $25 \%$ restante a productos tales como sebo, grasa, cerda, astas, cal, Ieña, frutas secas, etcétera. 
servado, por último, que mientras los textiles "de la tierra" originarios del área central mantienen una singular presencia en el mercado porteño, los caldos cuyanos prácticamente han desaparecido del mismo.

En sintesis, creemos que las apreciaciones formuladas sobre el tema para los años iniciales del periodo rosista conservan su vigencia, en términos generales, hacia el fin del mismo. Queda pendiente, entonces, una adecuada integración económica del espacio rioplatense, y el sistema rosista comienza a dar señales de agotamiento.

En efecto, hacia fines de la primera mitad del siglo XIX la estructura económica y las relaciones internacionales en que se basaba el régimen porteño habían ingresado en un proceso de cambio. La demanda de los productos que aportaba la ganadería - punta de lanza del sistema económico rosista-, en especial los cueros y la carne salada, había iniciado una curva descendente en los mercados extranjeros. A esto se sumaba la competencia que surgía, en el exterior, con el desarrollo de los saladeros del sur de Brasil, y en el plano interno, con el irrefutable ascenso de Entre Ríos, ascenso que, en realidad, tenía más implicaciones políticas que económicas, ${ }^{82}$ y que se había acelerado a partir de 1846, cuando pudo distraer sus esfuerzos del "Sitio Grande" para volcarlos en beneficio propio. ${ }^{83}$ Durante

82 Lynch, Repúblicas, 1991, pp. 292-293.

83 Si bien es cierto que el ascenso de Entre Ríos no puede competir con el de Buenos Aires, si fućramos estrictos y excluyéramos a las subregiones "Uruguay" y "Paraguay" del análisis y el bloqueo, su producción tiene salidas alternativas que eluden la vigilancia de Buenos Aires, ${ }^{84}$ por lo que, normalizada la situación, pareció una carga insostenible aceptar la imposibilidad de navegar libremente los ríos y la gravosa intermediación porteña, amén del injusto manejo de la cuestión arancelaria y los recursos aduaneros. Todos estos elementos conformaron un denso caldo de cultivo donde se fue gestando el ocaso del régimen rosista. Las provincias interiores, en tanto, sobrevivían gracias a sus conexiones con mercados vecinos, pero externos. En síntesis, hacia 1850 el peligro de desintegración económica del espacio rioplatense era algo tangible; en ese sentido, aspiramos a que el presente trabajo sobre los flujos mercantiles hacia el puerto aporte elementos de juicio sobre el tema.

las consideráramos como regiones exteriores, periféricas del espacio económico con núcleo en Buenos Aires-algo similar a lo planteado por Langer y Conti con respecto a las provincias norteñas argentinas y el espacio mercantil andino-, veríamos que aquél es mucho más importante de lo que puede suponerse a simple vista: más de $\mathbf{4 2 \%}$ del monto comerciado correspondería a Iintre Ríos. Si fiéramos todavia más allá - aún a ricsgo de forzar cl análisis-, teniendo cn cuenta que el peso del "Sitio Grande" recayó en su mayor parte sobre Entre Ríos (lo que implica movilización de tropas y recursos) podriamos considerar que lo que nosotros denominamos subrcgión "Uruguay" cstaba, en cierta forma, dominada por los entrerrianos de la zona oriental, construyendo una suerte de extensión geográfica y cconómica de la misma, con lo cual la participación de lintre Ríos en el monto comerciado ascendería a un sugerente $57 \%$.

${ }^{84}$ Halperin Donghi, Revolucion, 1980, p. 294. Assadourian, "Sector", 1983, p. 325. 


\section{APENDICE ESTADISTICO}

Cuadro 13. Flujo comercial hacia Buenos Aires: total de valores comerciados, 1831-1835

\begin{tabular}{|c|c|c|c|c|c|}
\hline Subregiones & 1831 & 1832 & 1833 & 1834 & 1835 \\
\hline \multicolumn{6}{|l|}{ Lttoral } \\
\hline $\begin{array}{l}\text { Buenos Aires } \\
\text { Santa Fe }\end{array}$ & $\begin{array}{l}448910 \\
554160\end{array}$ & 509085 & 418996 & 460215 & $\begin{array}{l}3208.00 \\
397990\end{array}$ \\
\hline Corrientes & 684650 & 651175 & 607800 & 1046920 & 960627 \\
\hline Entre Ríos* & 927865 & 1265946 & 1408194 & 1933181 & 1810078 \\
\hline Uruguay & 333416 & 705491 & 991670 & 1019534 & 1668841 \\
\hline Total regional & 2949001 & 4186614 & 4090888 & 4927894 & 5158366 \\
\hline \multicolumn{6}{|l|}{ Central } \\
\hline Sgo. Estero & - & 219800 & 96300 & 59350 & 74600 \\
\hline Tucumán & - & 676945 & 209750 & 308450 & 203750 \\
\hline Salta & - & 132050 & 80800 & 118450 & 98900 \\
\hline Jujuy & - & - & 25000 & 12400 & 12800 \\
\hline Catamarca & - & 24200 & 18150 & 16850 & - \\
\hline La Rioja & - & 20000 & 3000 & 1600 & \\
\hline Total regional & 636980 & 2708526 & 1297517 & 1664182 & 1131250 \\
\hline \multicolumn{6}{|l|}{ Cuyo } \\
\hline Mendoza & 81380 & 190560 & 201825 & 221490 & 116360 \\
\hline San Juan & 73520 & 246130 & 166578 & 111260 & 71420 \\
\hline San Luis & - & 63154 & 30430 & 6250 & 21610 \\
\hline Total regional & 154900 & 499844 & 398833 & 339000 & 209390 \\
\hline Total general & 3740881 & 7394984 & 5787238 & 6931076 & 6499006 \\
\hline \multicolumn{6}{|c|}{ " La subregión Entre Ríos puede dividirse en dos zonas: } \\
\hline & 1831 & 1832 & 1833 & 1834 & 1835 \\
\hline $\begin{array}{l}\text { Paraná } \\
\text { Costa occident }\end{array}$ & 504355 & 660780 & 723119 & 1066018 & 837925 \\
\hline río Uruguay & 423510 & 605166 & 685075 & 867163 & 972153 \\
\hline
\end{tabular}


Cuadro 14. Flujo comercial hacia Buenos Aires: total de valores comerciados, 1839-1850

\begin{tabular}{|c|c|c|c|c|c|c|}
\hline Subregtones & 1839 & 1840 & 1841 & 1842 & 1843 & 1844 \\
\hline \multicolumn{7}{|l|}{$\begin{array}{l}\text { Lttoral } \\
\text { Buenos }\end{array}$} \\
\hline Aires & 147872 & 101576 & 323963 & 1294935 & 1634758 & 1082440 \\
\hline Santa Fe & 349774 & 289171 & 3432839 & 3145487 & 3492994 & 3070293 \\
\hline Corrientes & 100483 & - & 162021 & 1217391 & 6028779 & - \\
\hline Entre Rios* & 322848 & 267081 & 17031759 & 10158069 & 11887555 & 11242595 \\
\hline Uruguay & - & 30350 & 5378534 & 2979855 & 17550971 & 14271076 \\
\hline Paraguay & - & - & 27725 & 45775 & 198275 & 471800 \\
\hline $\begin{array}{l}\text { Total } \\
\text { regional }\end{array}$ & 920977 & 688178 & 26356841 & 18841512 & 40793332 & 30138204 \\
\hline \multicolumn{7}{|l|}{ Central } \\
\hline Sgo. Estero & $\begin{array}{r}52985 \\
\end{array}$ & 281715 & $\begin{array}{r}579380 \\
579.321\end{array}$ & 890709 & 647940 & 353035 \\
\hline Tucumán & 565877 & 1081715 & 164300 & 2085195 & 1111662 & 756395 \\
\hline Salta & 21200 & 6000 & - & - & 73060 & 48590 \\
\hline Jujuy & 11520 & 8000 & - & - & - & - \\
\hline Catamarca & 2400 & - & - & 8000 & - & - \\
\hline La Rioja & - & - & - & - & - & - \\
\hline \multicolumn{6}{|l|}{ Total } & 3735026 \\
\hline \multicolumn{7}{|l|}{ Cuyo } \\
\hline Mendoza & 405251 & 373917 & 376050 & 675165 & 2286790 & 1546355 \\
\hline San Juan & 677047 & 1255957 & 429010 & 410107 & 1140273 & 562497 \\
\hline San Luis & 13699 & 36700 & 103750 & 39200 & 24056 & 7020 \\
\hline $\begin{array}{l}\text { Total } \\
\text { regional }\end{array}$ & 1095997 & 1666574 & 908810 & 1124472 & 3451119 & 2115872 \\
\hline $\begin{array}{l}\text { Total } \\
\text { general }\end{array}$ & 4242126 & 4651499 & 33212658 & 26622108 & 50035896 & 35989102 \\
\hline \multicolumn{7}{|c|}{ * La subregión Entre Ríos se puede dividir en dos zonas: } \\
\hline & 1839 & 1840 & 1841 & 1842 & 1843 & 1844 \\
\hline $\begin{array}{l}\text { Parana } \\
\text { Costa } \\
\text { occiden }\end{array}$ & 311022 & 197864 & 11229602 & 6743246 & 4766270 & 4801200 \\
\hline río Uruguay & 11826 & 69217 & 5802157 & 3414823 & 7121285 & 6441395 \\
\hline
\end{tabular}




\begin{tabular}{|c|c|c|c|c|c|c|}
\hline $\begin{array}{l}\text { Subregtones } \\
\text { Lttoral } \\
\text { Buenos }\end{array}$ & 1845 & 1846 & 1847 & 1848 & 1849 & 1850 \\
\hline Aires & 1137935 & 141639 & 537224 & 623374 & 740593 & 1373874 \\
\hline Santa Fe & 2756700 & 657567 & 2141199 & 4441380 & 4985488 & 5223511 \\
\hline Corrientes & 68020 & 11700 & 1981246 & 3788598 & 7454836 & 5935909 \\
\hline Entre Ríos* & 7596773 & 102649 & 1363755 & 11066856 & 17034872 & 17639289 \\
\hline Uruguay & 8795130 & 29754 & 202562 & 8124145 & 14318558 & 13049973 \\
\hline Paraguay & 92920 & - & 15000 & 383460 & 1008066 & 12480 \\
\hline $\begin{array}{l}\text { Total } \\
\text { regional }\end{array}$ & 20447478 & 943309 & 6240986 & 28427813 & 45542413 & 432350.36 \\
\hline Central & & & & & & \\
\hline $\begin{array}{l}\text { Cordoba } \\
\text { Sgo. Estero }\end{array}$ & $\begin{array}{r}221817 \\
568285\end{array}$ & $\begin{array}{r}23.37199 \\
217065\end{array}$ & $\begin{array}{r}2.314904 \\
363310\end{array}$ & $\begin{array}{r}2850.349 \\
749320\end{array}$ & $\begin{array}{r}531302 \\
531309\end{array}$ & 799388 \\
\hline Tucumán & 747229 & 820525 & 840946 & 1932275 & 1104634 & 1371431 \\
\hline Salta & 98250 & 11305 & - & - & - & 112800 \\
\hline Jujuy & - & - & - & - & - & - \\
\hline Catamarca & - & 30525 & 11322 & - & 5250 & - \\
\hline La Rioja & - & - & - & - & - & - \\
\hline
\end{tabular}

Total regional $\quad 3665581 \quad 3616619 \quad 3590482 \quad 5537944 \quad 5130755 \quad 4992345$ Cuyo $\begin{array}{llllllll}\text { Mendoza } & 1881331 & 700114 & 1958609 & 474873 & 242087 & 813118\end{array}$ $\begin{array}{lrrrrrr}\text { San Juan } & 435955 & 372226 & 1276822 & 682239 & 407236 & 289894 \\ \text { San Luis } & 24280 & - & 119320 & 291000 & 330361 & 431166\end{array}$

Total $\begin{array}{lllllllll}\text { regional } & 234566 & 1072340 & 3354751 & 1448112 & 979684 & 1534178\end{array}$ Total general $26454625 \quad 563226813186219354138695165285249761559$

- La subregión Entre Ríos se puede dividir en dos zonas:

$\begin{array}{lrrrrrr} & 1845 & 1846 & 1847 & 1848 & 1849 & 1850 \\ \begin{array}{l}\text { Paraná } \\ \begin{array}{l}\text { Costa } \\ \text { occidental }\end{array}\end{array} & 2897293 & 62448 & 920938 & 2695260 & 4214896 & 4802971 \\ \text { río Uruguay } & 4699480 & 40201 & 442817 & 8371596 & 12819976 & 12836318\end{array}$




\section{SECUENCIG}

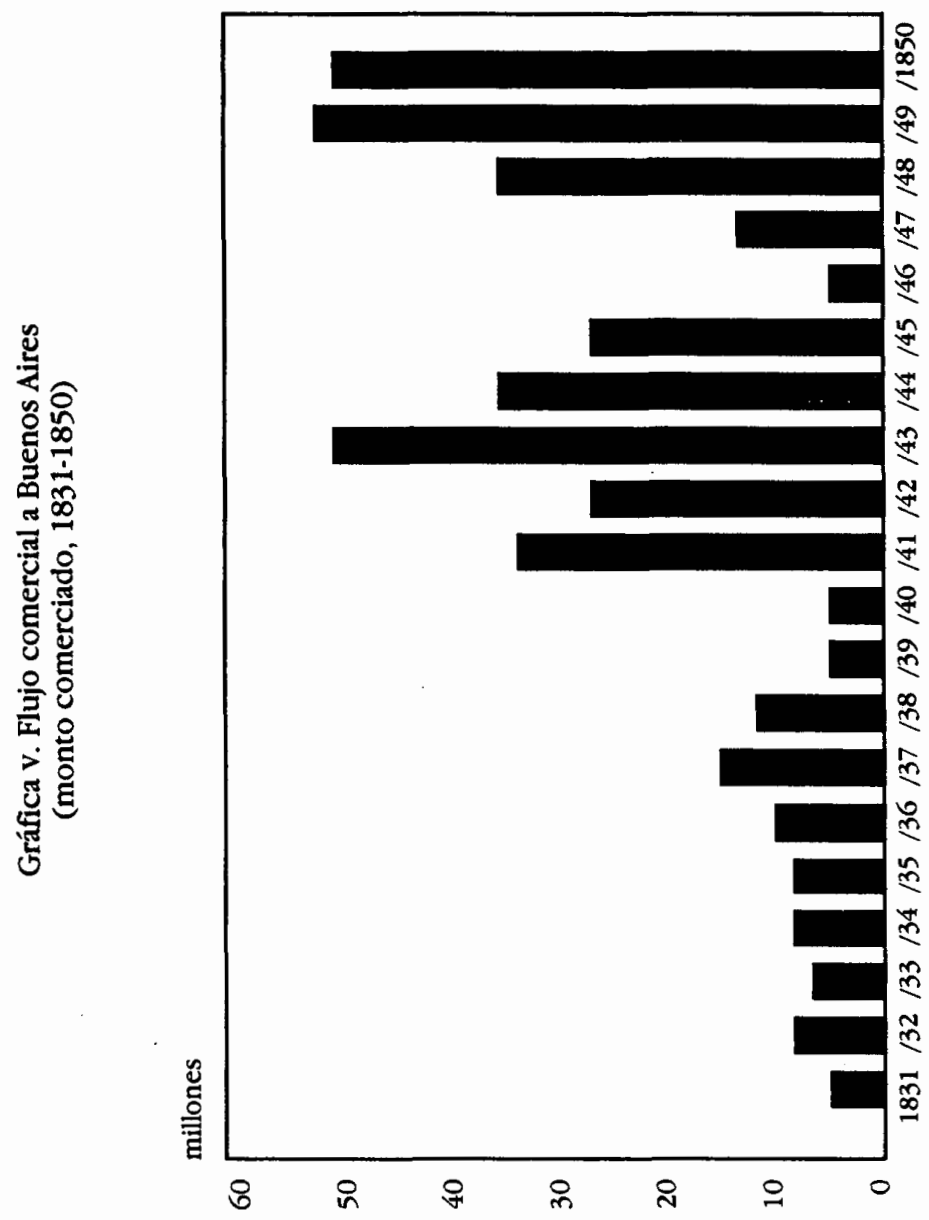




\section{SECUENCIA}

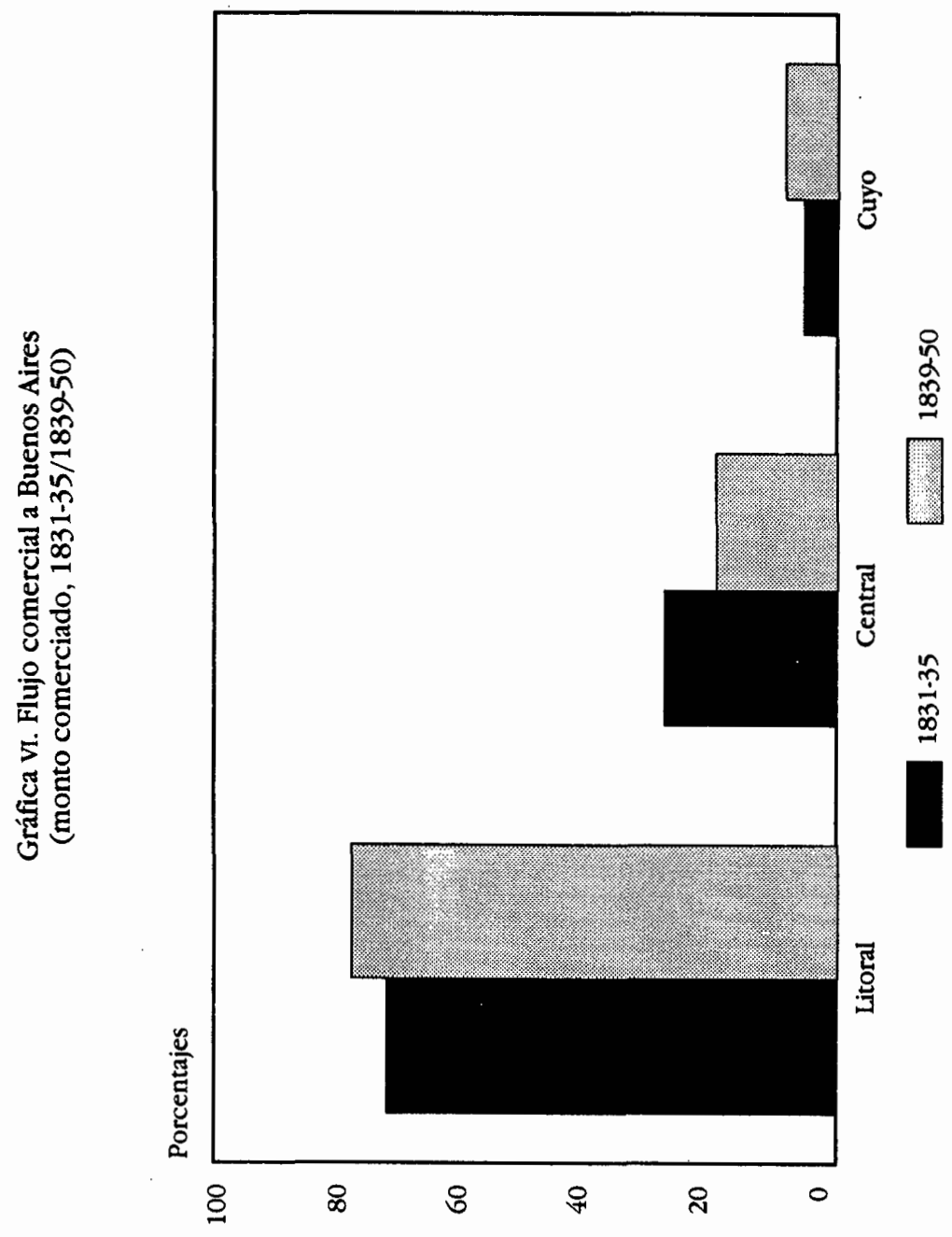


Cuadro 15. Flujos comerciales secundarios desde el Interior al puerto de Buenos Aires, 1831-1835

Subregiones Lana Trigo Maíz Tasajo Harina Cordobán Pellon

$\begin{array}{lrrrrrrr}\text { Litoral } & & & & & & \\ \text { Buenos Aires } & 15015 & 7404 & 15206 & - & 310 & 168 & 10 \\ \text { Santa Fe } & 10512 & 470 & 4537 & 2049 & 332 & - & - \\ \text { Corrientes } & 1907 & - & 408 & 5950 & - & - & - \\ \text { Entre Ríos } & 24370 & 1192 & 335 & 33905 & 128 & - & - \\ \text { Uruguay } & 6577 & 1602 & 194 & 84513 & - & - & - \\ \text { Total regional } & 58381 & 10671 & 20680 & 126417 & 770 & 168 & 10 \\ \begin{array}{l}\text { Central } \\ \text { Córdoba }\end{array} & 27750 & - & - & - & - & 2821 & - \\ \text { Sgo. Estero } & - & 22 & - & - & - & - & - \\ \text { Tucumán } & - & - & - & - & - & - & 231 \\ \text { Salta } & - & - & - & - & - & - & - \\ \text { Jujuy } & - & - & - & - & - & - & - \\ \text { Catamarca } & - & - & - & - & - & - & - \\ \text { La Rioja } & - & - & - & - & - & - & - \\ \text { Total regional } & 27750 & 22 & - & - & - & 2821 & 231 \\ \begin{array}{l}\text { Cuyo } \\ \text { Mendoza }\end{array} & 1218 & 21 & - & - & 2115 & - & - \\ \text { San Juan } & - & 2 & - & - & 478 & - & - \\ \text { San Luis } & - & - & - & - & - & - & - \\ \text { Total regional } & 1218 & 23 & - & - & 2593 & - & - \\ \text { Total general } & 87349 & 10716 & 20680 & 126417 & 3363 & 2989 & 241\end{array}$

Nota: La lana y la harina están expresadas en arrobas; el trigo y el maíz, en fanegas; los cordobanes y pellones, en unidades, y el tasajo en quintales (incluye unos pocos envíos de charque). 
Cuadro 16. Flujos comerciales secundarios desde el Interior al puerto de Buenos Aires, 1836-1838

\begin{tabular}{lrrrrrrr} 
Año & \multicolumn{1}{c}{ Lana } & Trigo & Maíz & \multicolumn{1}{c}{ Tasajo } & Harina & Cordobanes & Pellones \\
1836 & 21840 & 2287 & 370 & 43509 & 100 & 4810 & 4 \\
1837 & 66021 & 7427 & 16 & 88611 & 1200 & 41487 & 500 \\
1838 & 38775 & 1008 & 104 & 27025 & 10569 & 12668 & 632 \\
Total & 126636 & 10722 & 490 & 159145 & 11869 & 58965 & 1136
\end{tabular}

Nota: La lana y la harina están expresadas en arrobas; el trigo y el maíz en fanegas; los cordobanes y pellones, en unidades, y el tasajo, en quintales (incluye unos pocos envíos de charque).

Cuadro 17. Flujos comerciales secundarios desde el Interior al puerto de Buenos Aires, 1839-1850

\begin{tabular}{|c|c|c|c|c|c|c|c|}
\hline Subregiones & Lana & Trigo & Maíz & Tasajo & Harina & Condobán & Pellon \\
\hline Litoral & & & & & & & \\
\hline Bucnos Aires & 41452 & 3692 & 680 & - & 51519 & 6938 & 32 \\
\hline Santa Fe & 57990 & 8685 & 19197 & 707 & 7955 & 6627 & - \\
\hline Corrientes & 15939 & - & 656 & 45 & - & - & - \\
\hline Entre Ríos & 292687 & 40 & 312 & 11497 & 70 & - & - \\
\hline Uruguay & 131763 & 62 & 142 & 125342 & - & - & 22 \\
\hline Paraguay & - & - & 50 & - & - & - & - \\
\hline Total regional & 539831 & 12479 & 21037 & 137591 & 59544 & 13565 & 54 \\
\hline $\begin{array}{l}\text { Central } \\
\text { Córdoba }\end{array}$ & 500788 & 2043 & - & - & 53881 & 225894 & 544 \\
\hline Sgo. Estero & 35 & 103 & - & - & - & 450 & 467 \\
\hline Tucumán & 8.35 & 630 & - & - & 1073 & 2232 & 6758 \\
\hline Salta & - & - & - & - & - & - & 20 \\
\hline Jujuy & - & - & - & - & - & - & - \\
\hline Cátamarca & - & - & - & - & - & - & - \\
\hline La Rioja & - & - & - & - & - & - & - \\
\hline Total regional & 501658 & 2776 & - & - & 54954 & 228576 & 7789 \\
\hline Cuyo & & & & & & & \\
\hline Mendoza & 758 & 47 & - & - & 235759 & 7592 & - \\
\hline San Juan & - & 12 & - & - & 80626 & - & - \\
\hline San Luis & 21657 & - & - & - & 149 & 10500 & - \\
\hline Total regional & 22415 & 59 & - & - & 316534 & 18092 & - \\
\hline Total general & 1063904 & 15314 & 210,37 & 137591 & 431032 & 260233 & 7843 \\
\hline
\end{tabular}

Nơta: La lana y la harina están expresadas en arrobas; el trigo y el maíz, en fanegas; los cordobanes y pellones, en unidades, y el tasajo, en quintales (incluye unos pocos envios de charque).

EL INTERIOR FRENTE A BUENOS AIRES 
Cuadro 18. Porción que les corresponde a los cueros dentro del monto comerciado total, 1831-1850

\begin{tabular}{|c|c|c|c|c|c|}
\hline Años & $\begin{array}{c}\text { Monto } \\
\text { total }\end{array}$ & $\begin{array}{l}\text { Monto } \\
\text { cueros }\end{array}$ & Porcentaje & $\begin{array}{l}\text { Monto } \\
\text { cuero } \\
\text { vacuno }\end{array}$ & Porcentafe \\
\hline $\begin{array}{l}1831 \\
1832 \\
1833 \\
1834 \\
1835\end{array}$ & $\begin{array}{l}3740881 \\
7394984 \\
5787238 \\
6931076 \\
6499006\end{array}$ & 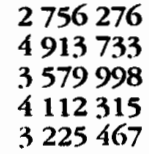 & $\begin{array}{l}73.68 \\
66.45 \\
61.86 \\
59.33 \\
49.63\end{array}$ & $\begin{array}{l}2290688 \\
4296758 \\
3212136 \\
3551112 \\
2695700\end{array}$ & $\begin{array}{l}61.23 \\
58.10 \\
55.50 \\
51.23 \\
41.48\end{array}$ \\
\hline \multicolumn{2}{|c|}{ Promedio (1831-1835) } & & 61.24 & & 52.87 \\
\hline $\begin{array}{l}1836 \\
1837 \\
1838\end{array}$ & $\begin{array}{r}7887751 \\
15385273 \\
8954031\end{array}$ & $\begin{array}{l}3780786 \\
7305564 \\
3727908\end{array}$ & $\begin{array}{l}47.93 \\
47.48 \\
41.63\end{array}$ & $\begin{array}{l}3245916 \\
6187685 \\
2878406\end{array}$ & $\begin{array}{l}41.15 \\
40.22 \\
32.15\end{array}$ \\
\hline \multicolumn{2}{|c|}{ Promedio (1836.1838) } & & 45.97 & & 38.20 \\
\hline $\begin{array}{l}1839 \\
1840 \\
1841 \\
1842 \\
1843 \\
1844 \\
1845 \\
1846 \\
1847 \\
1848 \\
1849 \\
1850\end{array}$ & $\begin{array}{rrr}4 & 242126 \\
4 & 651 & 499 \\
33 & 212658 \\
26 & 622108 \\
50035896 \\
35989102 \\
26454625 \\
5632268 \\
13186219 \\
35413869 \\
51652852 \\
49761559\end{array}$ & $\begin{array}{r}1573724 \\
1331632 \\
24209188 \\
20137031 \\
34411555 \\
25093387 \\
16371022 \\
1298302 \\
3478788 \\
15443220 \\
24620833 \\
27212766\end{array}$ & $\begin{array}{l}37.10 \\
28.63 \\
72.89 \\
75.64 \\
68.77 \\
69.72 \\
61.88 \\
23.05 \\
26.38 \\
43.61 \\
47.67 \\
54.69\end{array}$ & $\begin{array}{r}741380 \\
503472 \\
22774280 \\
18143625 \\
33650145 \\
24465992 \\
15438550 \\
722960 \\
2668955 \\
12540822 \\
20162852 \\
22911658\end{array}$ & $\begin{array}{l}17.48 \\
10.82 \\
68.57 \\
68.15 \\
67.25 \\
67.98 \\
58.36 \\
12.84 \\
20.24 \\
35.41 \\
39.04 \\
46.04\end{array}$ \\
\hline \multicolumn{3}{|c|}{ Promedio (18.39-1850) } & 57.94 & & 51.87 \\
\hline \multicolumn{3}{|c|}{ Promedio general (18.31-1850) } & 57.23 & & 50.84 \\
\hline
\end{tabular}




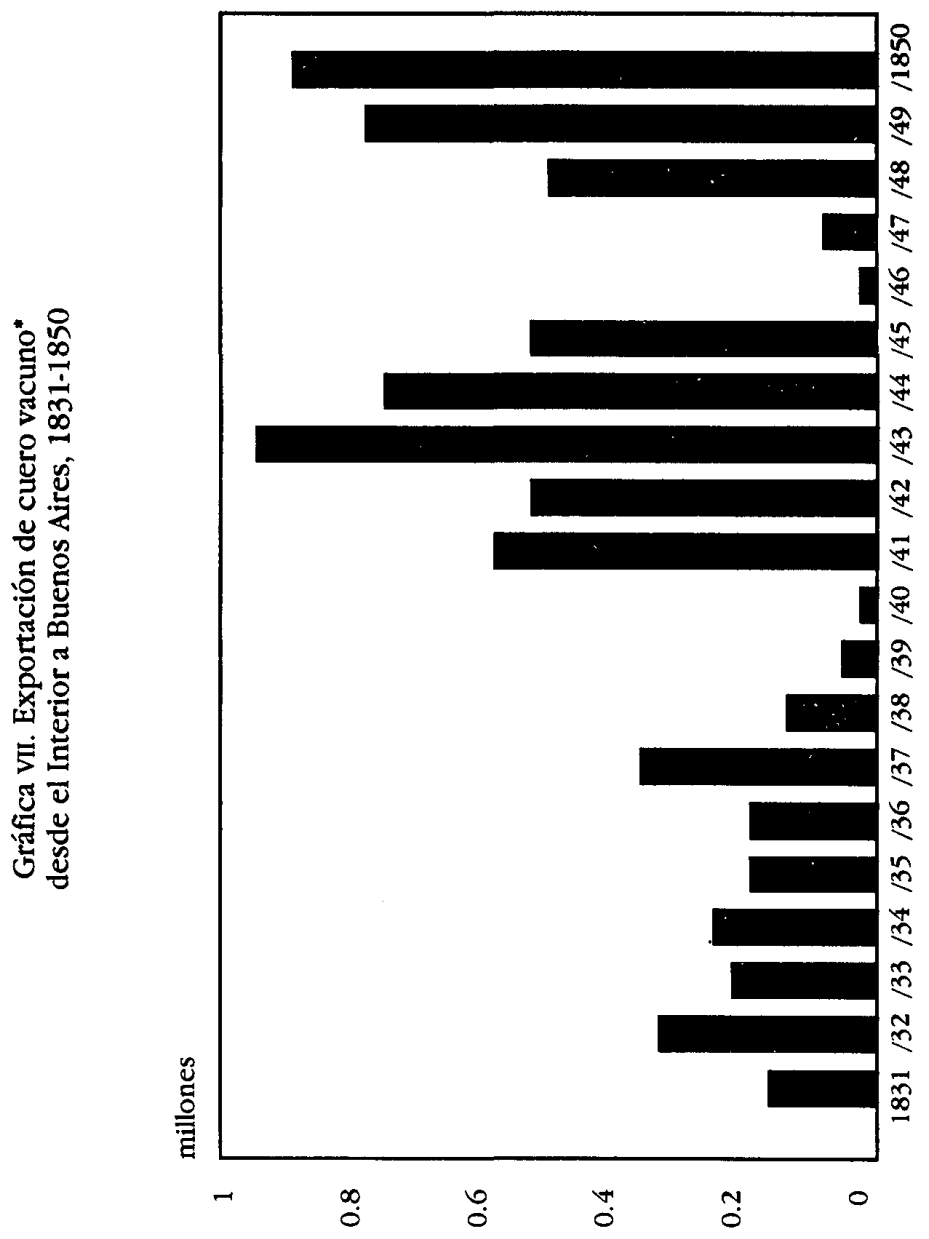


BIBLIOGRAFIA

-Amaral, Samuel, "Comercio libre y economías regionales. San Juan y Mendoza 17801820", Jahrbuch für Geschichte von Staat, Wirtschaft und Gesellschaft Latetnamericas, núm. 27, Kohl, 1990.

-Areces, Hidia R., y Mora E. Bowet, "Itapúa: comercio y frontera en el Paraguay del Dr. Francia; algunas consideraciones", Siglo $X I X$, año II, núm. 4, Facultad de Filosofía y Letras-UANL, Monterrey, julio-diciembre, 1987.

-Assadourian, Carlos Sempat, "El sector exportador de una economía regional del interior argentino. Córdoba 1800-1860. (Esquema cuantitativo y formas de producción.)", en C.S. Assadourian (comp.), El sistema de la economía colonial. El mercado intertor. Regiones y espacio económico, Nueva Imagen, México, 1983.

-Blasi, Hebe Judith, "Las relaciones comerciales entre las provincias y Buenos Aires", ponencia al Primer Congreso de Historia Argentina y Regional 1971, Academia Nacional de la Historia, Buenos Ajres, 1973.

-Broide, Julio, La evoluctón de los precios pecuarios argentinos en el periodo 1830-1850, Instituto de Economía Facultad de Ciencias Económicas-Universidad de Buenos Aires, Buenos Aires, 1951.

-Burgin, Miron, Aspectos econbmicos del federalismo argentino, Solar, 4a. ed., Buenos Aires, 1987.

-Cano, María Clelia et al., "Comercio interprovincial 1840-1850", ponencia al Primer Congreso de Historia Argentina y Regional 1971, Academia Nacional de Historia, Buenos Aires, 1973.

-Chiaramonte, José Carlos, Mercaderes del litoral. Economía y sociedad en la provincta de Corrientes, primera mitad del siglo $X I X$, Fondo de Cultura Económica, México, 1991. vincia del litoral, 1821-1841", Anuarto IEHS, núm. 1, 1986, uNCPBA, Tandil, 1987.

-, "Organización del Estado y construcción del orden social: la política económica de la provincia de Corrientes hacia 1821-1840", Anuarto IEHS, segunda época, núm. 11, Universidad Nacional de Rosario, Rosario, 1985. (Incluido en su obra Mercaderes del litoral, op. ctt.)

-, "Legalidad constitucional o caudillismo: el problema del orden social en el surgimiento de los estados autónomos del litoral argentino en la primera mitad del siglo XIX", Desarrollo Economtco, vol. 26, núm. 102, IDEs, Buenos Aires, julio-septiembre, 1986.

-Gamboni, Olga Dina, "Notas sobre la economía de Jujuy (1821-1830)", ponencia al Cuarto Congreso Nacional y Regional de Historia Argentina 1977, Academia Nacional de Historia, Buenos Aires, 1980.

-Garavaglia, Juan Carlos y Claudio Wentzel, "Un nuevo aporte a la historia del textil colonial: los ponchos frente al mercado porteño (1750-1850)", Anuario IEHS, núm. 4, 1989, UNCPBA, Tandil, 1990.

-Giberti, Horacio C. E., Historta economica de la ganadería argentina, Hyspamérica, Buenos Aires, 1985.

-Halperin Donghi, Tulio, De la revolu. ción de independencta a la confederactón rosista, Paidós, Buenos Aires, 1980.

$\longrightarrow$, Revoluctón y guerra, Siglo XXI Editores, Buenos Aires, 1972.

- "La expansión ganadera de la campaña de Buenos Aires (1810-1852)" Desarrollo Económico, vol. 3, núms. 1 y 2, IDES, Buenos Aires, abril-septiembre, 1963.

-Langer, Erick, "Espacios coloniales y economias nacionales: Bolivia y el norte argentino, 1810-1930", Siglo XIX, año II, núm. 4, Facultad de Filosofía y Letras-UANL, Monterrey, julio-diciembre 1987.

, y Viviana Conti, "Circuitos comerciales tradicionales y cambio económico en los Andes centromeridionales 
(1830-1930)", Desarrollo Econ6mico, vol. 31, núm. 121, IDES, Buenos Aires, abril-junio 1991.

-Lynch, John, "Las repúblicas del Río de la Plata", en Leslie Bethell (comp.), Historia de América Latina, 6. América Latina Independiente, 1820-1870, Editorial Crítica, Barcelona, 1991.

-Macchi, Manuel, Urquiza el saladertsta, Ediciones Macchi, Buenos Aires, 1971.

-McCaun, William, Viaje a caballo por las provincias argentinas, Hyspamérica, Buenos Aires, 1985.

-Mallo, Silvia Cristina et al., "El comercio entre Buenos Aires $y$ las provincias de 1830 a $1835^{n}$, ponencia al Primer Congreso de Historia Argentina y Regional 1971, Academia Nacional de la Historia, Buenos Aires, 1973.

-Palomeque, Silvia, "La circulación mercantil en las provincias del interior 1800 . 1810", Anuario, IEHs, núm. 4, 1989. UNCPBA, Tandil, 1990.

-Parish, Woodbine, Buenos Atres y las provinctas del Río de la Plata, Hachette, Buenos Aires, 1958.

-Rosal, Miguel Ángel, "Transportes terrestres y circulación de mercancías en el espacio rioplatense, 1781-1911", Anuario IEHS, núm. 3, 1988, unCPBA, Tandil, 1989.

- "El río de la Plata en la primera mitad del siglo xIx: las relaciones comerciales entre el interior y Buenos Aires, 1831-1835", Boletín del Instituto de Historia Argentina y Americana "Dr. Emilio Ravignani", tercera serie, núm. 5; Facultad de Filosofia y Letras-Universidad de Buenos Aires, primer semestre 1992.

-, "El río de la Plata en la primera mitad del siglo XIX: las relaciones comerciales entre el interior y Buenos Aires, 1840-1845; comparaciones con el periodo 1831-1835", Revtsta de Historia de América, del Instituto Panamericano de Geografia e Historia, 1992.

mitad del siglo XIX: las relaciones comercia- les entre el interior y Buenos Aires, hacia fines del periodo rosista", 1993, mimeografindo.

"Los transportes durante la primera década postrevolucionaria; la quiebra de un sistema", La Gaceta Amertcana, año II, vol. II, núm. 7, Buenos Aires, noviembre-diciembre de 1990.

-Saravi, Mario Guillermo, "Consideraciones acerca del Tratado entre Mendoza y Chile (1835)", ponencia al Cuarto Congreso Nacional y Regional de Historia Argentina 1977, Academia Nacional de Historia, Buenos Aires, 1980.

-Sarmiento, Domingo Faustino, Campaña en el Ejérctto grande (selección), Eudeba, Buenos Aires, 1962.

-Schmit, Roberto, "Mercados y flujos comerciales en los estados provinciales argentinos de la primera mitad del siglo XIX. El comercio de Corrientes en Buenos Aires (1822-1833)", Boletín del Instituto de Historia Argentina y Americana "Doctor Emilio Ravignani", tercera serie, núm. 4, Facultad de Filosolia y Letras-Universidad de Buenos Aires, Buenos Aires, segundo semestre 1991.

, La economía del interior en la primera mitad del siglo XIX (correlación de documentos). I. Cuyo, Academia Nacional de la Historia, Buenos Aires, 1981.

-Segreti, Carlos S. A., "Contribución al estudio del convenio particular mendocino-chileno de 1835 hasta la muerte del gobernador José Félix Aldao", ponencia al Cuarto Congreso Nacional y Regional de Historia Argentina 1977, Academia Nacional de Historia, Buenos Aires, 1980.

-Wentzel, Claudio, "El comercio del litoral de los ríos con Buenos Aires; el área del Paraná, 1783-1821", Anuario IEHS, núm. 3, 1988, uNCPBA, Tandil, 1989.

-Whigham, Thomas, "The back-door approach: The Alto Uruguay and paraguayan trade 1810-1852", Revista de Historia de América, núm. 109, Instituto Panamericano de Geografia e Historia, enero-junio 1990. 
SECUENCIG

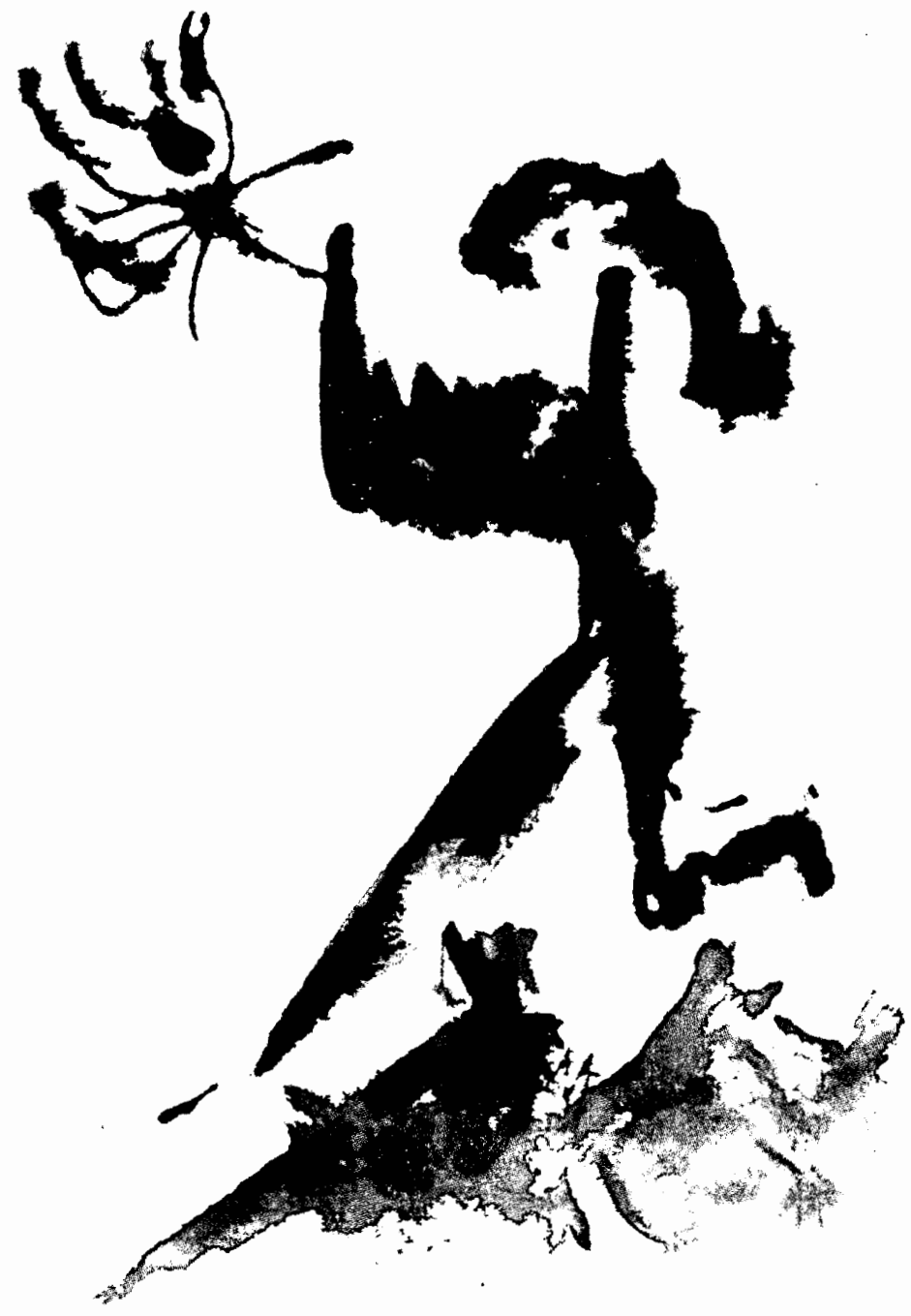

112 